\title{
Markets for jobs and their task overlap ${ }^{\text {is }}$
}

\author{
Maarten Goos ${ }^{\mathrm{a}, *}$, Emilie Rademakers ${ }^{\mathrm{a}, \mathrm{b}}$, Anna Salomons ${ }^{\mathrm{a}}$, Bert Willekens ${ }^{\mathrm{b}}$

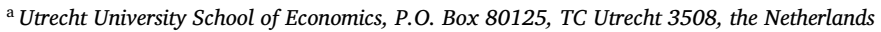 \\ ${ }^{\mathrm{b}}$ University of Leuven, Department of Economics, Naamsestraat 69, Leuven 3000, Belgium
}

\section{A R T I C L E I N F O}

\section{JEL classification:}

$\mathrm{J} 24$

J62

J64

O33

Keywords:

Job search

Markets for jobs

Task competencies

Task overlap between job markets

Winners and losers from automation

\begin{abstract}
A B S T R A C T
We show that tightness in markets for jobs for which an unemployed job seeker fully qualifies in terms of her task competencies is predictive of her unemployment duration. This suggests that the labour market is organized along jobs and their task content. We also find that unemployed job seekers do not compete in markets where they possess only part of the required task competencies, suggesting that task overlap across jobs is unimportant for worker mobility between job markets. This implies that adverse task-biased shocks are likely to have pronounced distributional consequences across workers with different task competencies. To illustrate this, we quantify the impact of technological progress that automates routine tasks, showing that this imposes substantial adjustment costs that are highly unevenly distributed across unemployed job seekers with routine versus non-routine task competencies.
\end{abstract}

\section{Introduction}

A long and growing literature has shown that labour markets are undergoing structural change due to ongoing technological progress: as codifiable or "routine" tasks are automated by digital technologies, the demand for labour in jobs which intensively perform routine tasks is reduced relative to other tasks (see Acemoglu and Autor (2011) for an overview). Consequently, workers in routine-task intensive jobs will reallocate towards jobs that are less routine-task intensive, leading to structural change in the composition of jobs and their relative wages. However, despite an extensive literature examining the reallocation of workers across jobs, there is relatively little work that directly tests whether the labour market is organised along jobs and their task content, i.e. that there are markets for jobs.

Following automation, the reallocation of displaced workers towards new jobs can be costly for those workers if they cannot easily switch to other jobs for which they are less specialized in terms of their task competencies. In the scenario where markets for jobs overlap because of common task content, the impact of the automation of routine tasks would tend to diffuse, lessening its impact on any one group of workers.
But if job markets are mostly insular, automation is mainly felt locally by workers with routine-task competencies, leading to those workers carrying most of the burden of adjustment. Although the idea that technological progress or any other task-biased shock results in winners and losers is not new (see, for example, Autor et al. (2015)), there is little empirical evidence that quantifies the distributional consequences of such shocks across workers with different task competencies.

To address these issues, this paper examines labour market outcomes of unemployed job seekers with different task competencies. ${ }^{1}$ The paper (i) examines whether the labour market is organized along jobs, defined as detailed occupation-experience cells and their corresponding tasks, and estimates the importance of overlap across jobs based on their common task content; and (ii) uses these estimates to assess the distributional consequences of the automation of routine tasks for

\footnotetext{
${ }^{1}$ Unemployment spells are a particularly important margin to consider given their long-term scarring effects on the careers of workers as well as their adverse health consequences (Davis and von Wachter 2011; Jacobson et al. 1993; Sullivan and von Wachter 2009).
}

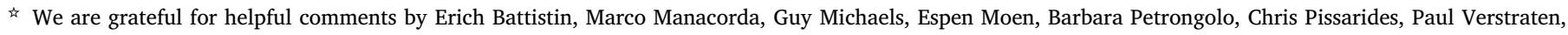

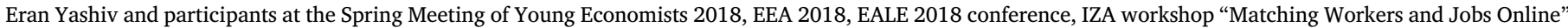

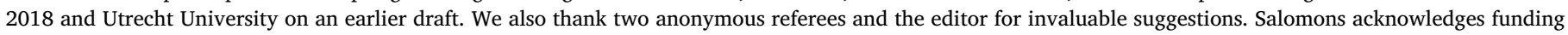

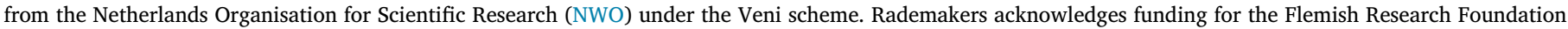

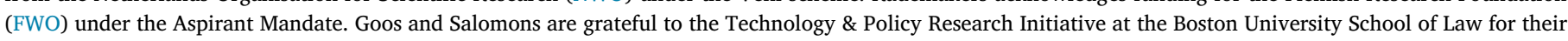
financial support.

* Corresponding author.

E-mail address: m.goos@uu.nl (M. Goos).
} 
unemployment durations across unemployed job seekers with different task competencies. Regarding (i), we find that the labour market is, at least in part, organized along jobs for which an unemployed job seeker fully qualifies in terms of her task competencies. We also find that there is overlap across jobs in terms of their task content - i.e. unemployed job seekers also compete for jobs for which they only partially qualify in terms of their task competencies. But the extent of this task overlap is quite limited: unemployed job seekers can only compete for jobs for which they have the large majority of all required task competencies. These results are direct evidence that markets for jobs and their task content are important for understanding job search. Regarding (ii), limited importance of task overlap across jobs implies that the automation of routine tasks (or any other task-biased shock) can have pronounced distributional consequences for unemployment durations across unemployed job seekers with different task competencies. In particular, we quantify by how much unemployed job seekers with mainly routinetask competencies are disproportionately hurt by ongoing automation.

Our empirical approach is to estimate a well-established empirical model capturing job search externalities (see Petrongolo and Pissarides (2001) for an overview), making use of the positive relationship between the re-employment probability of an unemployed job seeker and her labour market tightness, defined as the number of vacancies relative to the number of unemployed job seekers across all jobs that are relevant to her. In particular, we relate a job seeker's expected unemployment duration to the average tightness she faces across jobs for which she fully or partially qualifies in terms of her task competencies. Because our definition of an unemployed job seeker's relevant labour market also includes those jobs for which she only partially qualifies, we account for the importance of task overlap across jobs in labour markets.

To model task overlap, we build on (Manning and Petrongolo, 2017) who estimate the extent of spatial overlap in job search. Their analysis defines markets as disaggregated geographical units but allows local labour markets to overlap, i.e. for tightness in geographically close-by markets to influence the re-employment probability of a job seeker in a given locality. ${ }^{2}$ Their estimates show evidence of high costs of distance, but they also find that policies targeted at a specific local labour market have limited impact because important ripple effects diffuse their impacts through surrounding areas. Our analysis adapts their approach by defining distance as task dissimilarities between jobs.

The main contribution of this paper is that it provides direct evidence in support of the idea that labour markets are, at least in part, organized along detailed jobs and their corresponding tasks. To show this, we use representative data on unemployed job seekers and vacancies from an online job search platform in Belgium. The data contains detailed information on unemployed job seekers' task competencies as well as vacancies' task requirements across jobs, where a job is defined as an occupation-experience cell taken from the highly disaggregate ROMEV3 classification of jobs and their related task descriptions. We observe over 2000 jobs and 3000 tasks, with each job consisting of 7 tasks on average. For each of the 139,944 unemployed job seekers that we observe on the online platform in 8 repeated cross-sections during 2013-2014, we merge individual-level administrative data from different sources on their employment histories between 2010-2015 together with a number of person characteristics. Based on these data, the importance of jobs and their task content is shown by the predictive power of job market tightness over re-employment probabilities of unemployed job seekers. Moreover, we show the existence of spillovers in search externalities between jobs that have more than $80 \%$ of their tasks in common. However, we also find substantial rigidities for unemployed job seekers to compete for jobs for which they do not have the large majority of re-

\footnotetext{
2 In particular, Manning and Petrongolo (2017) use unemployment and vacancy data on 8850 Census wards in England and Wales, and combine these with micro data on wages and the use of transport modes to model commuting costs as the distance between any two wards.
}

quired task competencies. These rigidities have important consequences for the distributional impacts of task-biased shocks.

To illustrate this, this paper also quantifies the distributional effects of automation, captured by an adverse routine-biased task shock in vacancies, on job seekers' unemployment durations. In a benchmark scenario of a single labour market where task competencies don't matter and each unemployed job seeker can compete for each vacancy, expected unemployment duration would increase the same for all job seekers in response to automation. We then compare this increase to the distribution of changes in unemployment durations under the actually estimated importance of task overlap across jobs, finding substantial differences between unemployed job seekers with different task competencies. Indeed, following automation, unemployed job seekers with mainly routine-task competencies experience a fourfold increase in their unemployment durations compared to the single labour market scenario. To the contrary, unemployed job seekers with non-routine task competencies are largely insulated from automation, suggesting that active labour market policies should only target disadvantaged job seekers with routine-task competencies.

\section{Related literature}

Closely related to our paper is (Cortes et al., 2016) who examine worker flows. In particular, they study transition rates of US workers between routine jobs, non-routine jobs, and unemployment or labor force non-participation. In their analyses, two-thirds of the long-run decline in routine employment between 1976 and 2012 is explained by two changes. The first is a rise in the job-separation rate from routine jobs into non-participation, especially before 2007. The second is a decrease in job finding rates for the unemployed and non-participants into routine jobs, especially after $2007 .^{3}$ This recent fall in job finding rates for unemployed job seekers in routine jobs is consistent with our findings, although the set-up in our paper deviates in several important ways from Cortes et al. (2016)). Perhaps the most important differences are that we use an alternative empirical strategy that exploits the heterogeneity across unemployed job seekers in terms of their task competencies, and that we explicitly assume an adverse routine-biased task shock in vacancies to quantify the distributional consequences of ongoing automation across unemployed job seekers with different task competencies.

Also closely related to our paper is (Autor and Dorn, 2013) who use US Census data between 1950 and 2005 to assess the importance of technological change on relative employment and wages across occupations within local labour markets, and on migration patterns by skill-type between local labour markets. Consistent with our results, they find that technological change has reduced employment in routine-task intensive jobs, especially in local labour markets where the share of workers doing routine tasks was high initially. However, Autor and Dorn (2013) do not explicitly examine the impact of ongoing technological progress on the transition from unemployment into employment, as we do in this paper.

Autor et al. (2013) use the same US local labour markets as their level of analyses to show direct evidence that international trade can increase unemployment locally. In particular, they find that local labour markets that are exposed to China's rising competitiveness in product markets experience an increase in unemployment. ${ }^{4}$ This is evidence that

\footnotetext{
${ }^{3}$ Cortes et al. (2016) also examine for which demographic groups these transition rates from unemployment and non-participation into routine jobs have fallen the most. They find that lower propensities to transition into routine manual jobs are particularly acute for males, the young, and low levels of education. Moreover, the fall in the propensity to transition from unemployment into routine cognitive jobs is particularly strong for whites, females, the primeaged, and those with higher levels of education. Related evidence is presented in Cortes et al. (2017).

${ }^{4}$ Comparing the impact of technological change to the impact of increased import competition from China on employment in local labour markets,
} 
free trade not only produces winners (e.g. consumers who can buy some products for less money) but also some clear losers. These findings have sparked a lively debate about the distributional consequences of international trade for workers. ${ }^{5}$ We add to this debate by quantifying the heterogeneity in adjustment costs across unemployed job seekers with task competencies following ongoing automation.

None of the studies that were mentioned so far in this section explicitly consider the possibility that there is task overlap across jobs in labour markets. There is, however, a small but growing literature that explicitly addresses the importance of task overlap across jobs. Most recently, Cortes and Gallipoli (2018) use monthly data of US workers to estimate their costs of occupational switching, where the distance between any two occupations depends on their task overlap. Starting from a model of occupational choice, they derive an empirical expression that relates worker flows to the task distance between occupations as well as to occupation-specific entry costs that are independent of task overlap. Consistent with our findings, Cortes and Gallipoli (2018) find that task distance between occupations is important in explaining worker flows between occupations. However, our paper differs from theirs in that our study doesn't look at job-to-job mobility but at transitions of unemployed job seekers into employment. Moreover, as is common in this literature, Cortes and Gallipoli (2018) analyse fewer than 40 occupations and 15 tasks, whereas we use a much more finely grained job classification based on detailed occupation-experience cells and related task descriptions for each of these cells. This is important since broad occupational categories may be very heterogeneous in terms of the experience and tasks they require, such that a finely grained occupationexperience and task classification is needed.

Other studies on the costs of job switching have relied exclusively on wage data, particularly on the wage changes experienced by workers when transiting into employment in a new firm, occupation or industry. Using this empirical approach, Gathmann and Schonberg (2010) and Poletaev and Robinson (2008) also find evidence for the importance of task overlap and of task-specific human capital for wages. More recently, Robinson (2018) distinguishes between wage changes after voluntary and involuntary occupational switches. Even though the task distance may be equal for two sets of occupations, the implication for task specific human capital and therefore wage changes may be different depending on the type of switch. Robinson (2018) finds that task dissimilarity leads to negative wage effects only when the switch was involuntary. This is consistent with our findings that, after job displacement, the mobility of workers into jobs for which they do not have most of the required task competencies is limited.

Our empirical approach is based on a search-and-matching framework by relating job seekers' unemployment durations to their labour market tightness, defined as the ratio of vacancies to unemployed job seekers in occupation-experience cells for which unemployed job seekers fully or partially qualify in terms of their task competencies. The market dimension for most applications of search-and-matching frameworks has been geographic units or sectors. For example, Manning and Petrongolo (2017) allow for spatial overlap in job search to conclude that there are high costs of geographical distance, but also that there are important ripple effects of local labour market policies through surrounding areas. These findings are corroborated in a recent study by Marinescu and Rathelot (2018) who find that workers dislike applying to geographically distant jobs, but that this distaste for distance is fairly inconsequential for aggregate unemployment because job seekers tend to be close enough to vacancies on average.

Autor et al. (2015) conclude that rising Chinese imports results in significant falls in employment, whereas local labour markets specialized in routine-task intensive activities experience occupational polarization but not a net decline in employment.

5 See, for example, https://www.technologyreview.com/s/602101/the-tradeoffs-of-free-trade/.
Finally, there is a small but growing literature that uses a searchand-matching framework to analyse markets for jobs that are not necessarily geographically close or in the same sector. For example, using German administrative data, Fahr and Sunde (2004) show that there is substantial heterogeneity in the job creation process at the disaggregated occupational level. Dengler et al. (2016) use similar data to estimate an occupation-specific matching efficiency, finding substantial heterogeneity linked to different levels of standardization and variation in job requirements. Stops (2014) looks at correlations between occupational markets on the basis of training requirements in the German labour market to improve estimates of occupational matching elasticities. But none of these studies considers task overlap across jobs, as we do here.

The remainder of this paper is organized as follows. We first describe our data in Section 3. Next we outline our empirical approach and provide evidence in support of markets for jobs in Section 4. Section 5 show that heterogeneity across unemployed job seekers' task-competency profiles is limited: our results do not differ much across unemployed job seekers with routine or non-routine and manual or cognitive taskcompetency profiles. As an illustration of the importance of our main findings in Sections 4 and 5, Section 6 quantifies the distributional consequences of ongoing automation across unemployed job seekers with different task competencies. Finally, Section 7 concludes.

\section{Data}

Our main data consists of job seekers and vacancies taken from the Flemish public employment service (VDAB) in 2013-2014: we refer to this as the VDAB sample. ${ }^{6}$ Auxiliary data come from social security records containing the employment history between 2010-2015 and personal characteristics of each job seeker observed in the VDAB sample. Section 3.1 first describes the institutional setting, Section 3.2 describes the VDAB sample, and Section 3.3 then discusses our auxiliary data sources.

\subsection{Institutional setting: VDAB's online job platform}

Our main data are taken from VDAB's online job platform, called "Mijn Loopbaan" (which translates to "My Career"), introduced by VDAB in 2012 to help match job seekers to vacancies. For job seekers, the platform serves as a portal to various services provided by the public employment service, including the creation of a task-competency profile.

Any individual can register as a job seeker on VDAB's online job platform free of charge. For job seekers claiming unemployment benefits, registration is compulsory and use of the platform is part of mandatory meetings with caseworkers. When registering on the platform, each job seeker must list her occupation-specific experiences by indicating at least one occupation-experience cell in ROME-V3. ${ }^{7}$ ROME-V3 was originally designed by the French public employment service as an inventory of jobs, defined as detailed occupation-experience cells and their task content, that can be consulted by job seekers and employers for orientation, similarly to the US O*NET. ${ }^{8}$ This results in 676 occupations and 3 experience levels in each of these occupations (less than two years; between 2 and 5 years; and more than 5 years of experience), or

\footnotetext{
${ }^{6}$ Flanders, the Flemish Region of Belgium, is the Dutch-speaking area in the country's north, and one of 3 Belgian regions. It has a population of about 6.5 million, out of some 11.3 million for the entire country.

${ }^{7}$ As part of the application profile, job seekers must also indicate whether they are looking for full-time or part-time employment or are open to both. This information will also be used in the analyses below.

${ }^{8}$ ROME-V3 stands for Répertoire Opérationnel des Métiers et des Emplois, 3rd version. ROME-V3 can be mapped into the more standard ISCO88 occupation classification. For more details about ISCO88, see http://www.ilo.org/public/english/bureau/stat/isco/isco88/major.htm.
} 
a potential 2028 (676 occupations $\times 3$ experience levels) occupationexperience cells, which we call "jobs". Related to these 2028 jobs are 3489 tasks, with each job containing 7 tasks on average. The task measures related to the job experiences listed by a job seeker allow us to construct that job seeker's task-competency profile.

Job vacancies come from two broad sources. Firstly, private and public employers can directly post vacancies on VDAB's online job platform free of charge. This channel accounts for around 55\% of all vacancies. Employers that directly post a vacancy on the platform must register online and submit a form with details about location, occupation, and required experience based on ROME-V3. Secondly, VDAB exchanges vacancy information with several private and public labour market intermediaries (e.g. Randstad, Manpower, regional public employment services) making up for the remaining $45 \%$ of vacancies. Each of these exchanged vacancies is registered as requiring a certain occupation and experience level that is matched by VDAB to the ROME-V3 classification of jobs.

\subsection{VDAB sample}

Our VDAB sample is a sample of unemployed job seekers and vacancies taken from VDAB's online job platform at the end of the first month of every quarter of 2013 and 2014, resulting in 8 crosssections. ${ }^{9}$ To further organize the discussion of our VDAB sample, Sections 3.2.1 and 3.2.2 discuss the data we collected from the online job platform about unemployed job seekers and job vacancies respectively. Next, Section 3.2.3 explains in more detail how information about tasks is organized in our data. Finally, Section 3.2.4 ends with a discussion of the representativeness of our VDAB sample.

\subsubsection{Job seekers}

Although any individual, either employed or unemployed, can register as a job seeker on VDAB's online job platform, we restrict our analyses to unemployed job seekers since our focus is on unemployment durations as the outcome variable. ${ }^{10}$ Columns (1) and (2) of Table 1 show shares of unemployed job seekers' listed jobs (i.e. occupation-experience cells) to indicate their task competencies in ROME-V3, aggregated across 27 2-digit ISCO88 occupation groups and averaged across our 8 crosssections. Given that unemployed job seekers can list more than one job to state their task competencies, column (1) of Table 1 reports shares only using the first listed job by each unemployed job seeker, whereas column (2) uses all listed jobs. ${ }^{11}$

Column (1) shows that the fraction of jobs stated by unemployed job seekers is high for medium-skilled "other associate professionals" (2digit ISCO88 code 34), performing a wide range of practical white-collar tasks; medium-skilled "office clerks" (41); various less-skilled personal services (51, 52 and 91); and less-skilled (often assisting) "labourers in mining, construction, manufacturing and transport" (93). Occupations for which unemployed job seekers have relatively few task competencies are in part more sector specific such as "armed forces" (01); mediumskilled "teaching associate professionals" (33), mainly providing education and care for children below primary school age; medium-skilled "precision, handicraft, printing and related trades workers" (73), making or repairing specific products such as musical instruments, jewellery, precious metalwork, ceramics, porcelain, or book-binding; or less-skilled "agriculture, fishery and related labourers" (92). Other jobs for which unemployed job seekers have relatively few task competencies require high skill levels, such as "legislators and senior officials" (11); "general

\footnotetext{
9 See Appendix A for further details about the sampling procedure.

10 Employed job seekers account for $22 \%$ of all (employed or unemployed) job seekers observed on VDAB's online job platform. Including employed job seekers on the right-hand side of Eq. (1) below does not affect our results.

11 To discount for the possibility that an unemployed job seeker can state multiple jobs, column (2) weighs each job by the inverse of the total number of jobs listed by the same unemployed job seeker. Job seekers list 2.6 jobs on average.
}

managers" (13); "physical, mathematical and engineering science professionals" (21); or "life science and health professionals" (22). Finally, note that the shares in column (2) differ little from those in column (1).

The bottom three rows of Table 1 provide additional information about the size of the VDAB sample. The third last row of column (1) (labelled "N jobs") reports that, in the average cross-section, unemployed job seekers indicate 1158 different jobs out of a potential 2028 in ROME-V3. The before-last row of column (1) (labelled "N sample") indicates that there are 17,493 unemployed job seekers in the average cross-section, resulting in 139,944 (17,493 unemployed job seekers per cross-section $\times 8$ cross-sections) unemployed job seekers and, hence, unemployment spells in our VDAB sample. The last row of Table 1 (labelled "N platform") shows the number of all unemployed job seekers registered on VDAB's online job platform in the average quarter during the period 2013-2014, equal to 229,535 . $^{12}$

\subsubsection{Vacancies}

Column (3) of Table 1 shows how vacancies are distributed across aggregate 2-digit ISCO88 occupation groups, with shares again averaged across the 8 cross-sections in our sample. The rank correlation coefficient between columns (1) and (3) is a high and statistically significant 0.77 , mainly reflecting that some jobs are generally larger than others in the labour market. But there are also substantial differences between the shares reported in columns (1) and (3) for some occupation groups. For example, the share of vacancies posted for less-skilled labourers (ISCO88 93) is much lower than its share of unemployed job seekers for these occupations. On the other hand, the shares of vacancies for high-skilled corporate managers (ISCO88 12) and physical, mathematical and engineering (associate) professionals (ISCO88 21 and 31) are much higher than their shares for unemployed job seekers' task competencies. All in all, this suggests that there is substantial variation across jobs in their labour market tightness, defined as the number of vacancies over the number of unemployed job seekers for any given job.

The third row from the bottom in column (3) informs that, in the average cross-section in our sample, employers post vacancies in 877 different jobs out of a potential 2028 in ROME-V3. The before-last row in column (3) gives the average number of vacancies in each cross-section in our sample, equal to 11,228 , whereas the last row of column (3) shows that the total number of vacancies posted on the job platform is 70,407. Comparing the last row in columns (1) and (3) suggests that there are on average 3 unemployed job seekers per vacancy at each point in time between 2013-2014. This is in line with other estimates for this period: 3.5 for the Netherlands (CBS Statline); 6.2 in Germany, 4.3 in Norway, 4 in Sweden, and 2.1 in the UK (OECD STATS); and 2.5 in the US (JOLTS and BLS).

\subsubsection{Tasks in ROME-V3}

The ROME-V3 classification also links each job to a set of required task competencies. The task classification in ROME-V3 is very detailed: there are 3489 tasks linked to 2028 jobs. On average, a job consists of 7 different tasks. Some of these tasks are specific to any one job, but many are not. In particular, Fig. 1 plots a histogram of the number of jobs in which any one task appears in ROME-V3. This shows that the same task appears in 4 jobs on average. The median is 2 , and the first and third quartiles are 2 and 3 respectively. For ease of inspection, we censored the figure at any task occurring in 50 jobs. ${ }^{13}$ Examples of tasks that are most common across jobs are stock taking; ordering of inputs with suppliers; accepting payments; or the coordination of teams.

Another way to summarize the task data in ROME-V3 is by defining task overlap across jobs. As an example, column (1) of Table 2 shows the 8 tasks for the most frequent job stated by unemployed job seekers

\footnotetext{
12 The total number of unemployed job seekers registered on VDAB's online job platform is taken from https://arvastat.vdab.be and is the number of registered unemployed job seekers in any month averaged over the period 2013-2014.

${ }^{13}$ Some tasks appear in up to 168 jobs.
} 
Table 1

Shares of unemployed job seekers and vacancies across occupation groups.

\begin{tabular}{|c|c|c|c|}
\hline & $\begin{array}{l}\% \text { listed occupations, first } \\
\text { (1) }\end{array}$ & $\begin{array}{l}\text { \% listed occupations, all } \\
\text { (2) }\end{array}$ & $\begin{array}{l}\text { \% vacancies } \\
\text { (3) }\end{array}$ \\
\hline 01: armed forces & 0.03 & 0.03 & 0.04 \\
\hline 11: legislators and senior officials & 0.18 & 0.22 & 0.43 \\
\hline 12: corporate managers & 5.56 & 5.55 & 18.97 \\
\hline 13: general managers & 0.08 & 0.10 & 0.11 \\
\hline 21: physical, mathematical and engineering science professionals & 0.83 & 0.82 & 3.38 \\
\hline 22: life science and health professionals & 0.18 & 0.17 & 0.49 \\
\hline 23: teaching professionals & 2.96 & 3.11 & 2.13 \\
\hline 24: other professionals & 4.95 & 4.54 & 5.05 \\
\hline 31: physical and engineering science associate professionals & 2.17 & 2.13 & 7.69 \\
\hline 32: life science and health associate professionals & 1.68 & 1.56 & 1.67 \\
\hline 33: teaching associate professionals & 0.00 & 0.01 & 0.01 \\
\hline 34: other associate professionals & 8.91 & 8.54 & 15.46 \\
\hline 41: office clerks & 9.43 & 9.28 & 5.92 \\
\hline 42: customer services clerks & 2.93 & 3.31 & 1.88 \\
\hline 51: personal and protective services workers & 7.82 & 7.94 & 3.69 \\
\hline 52: models, salespersons and demonstrators & 8.14 & 8.24 & 5.30 \\
\hline 61: market-oriented skilled agricultural and fishery workers & 1.35 & 1.41 & 0.35 \\
\hline 71: extraction and building trades workers & 5.21 & 5.26 & 5.08 \\
\hline 72: metal, machinery and related trades workers & 3.26 & 3.07 & 6.16 \\
\hline 73: precision, handicraft, printing and related trades workers & 0.59 & 0.52 & 0.19 \\
\hline 74: other craft and related trades workers & 0.86 & 0.87 & 1.11 \\
\hline 81: stationary-plant and related operators & 0.29 & 0.31 & 0.32 \\
\hline 82: machine operators and assemblers & 3.18 & 3.37 & 2.99 \\
\hline 83: drivers and mobile-plant operators & 5.53 & 5.94 & 3.55 \\
\hline 91: sales and services elementary occupations & 7.56 & 8.81 & 6.40 \\
\hline 92: agricultural, fishery and related labourers & 0.64 & 0.70 & 0.10 \\
\hline 93: labourers in mining, construction, manufacturing and transport & 15.69 & 14.21 & 1.52 \\
\hline $\mathrm{N}$ jobs & 1158 & 1460 & 877 \\
\hline N sample & 17493 & 17493 & 11228 \\
\hline $\mathrm{N}$ platform & 229535 & 229535 & 70407 \\
\hline
\end{tabular}

Source: VDAB: Mijn Loopbaan; VDAB Arvastat. Notes: Job seekers and vacancies are pooled across occupation cells to 2-digit ISCO88 groups. Shares are averaged across time observations.

Table 2

Examples of occupation-experience cells and their task contents in ROME-V3.

\begin{tabular}{|c|c|c|}
\hline $\begin{array}{l}\text { (1) } \\
\text { Occupation-experience cell } \\
\text { Production worker, }<2 \text { years (total n. of tasks=8) } \\
\text { ISCO } 88=93\end{array}$ & $\begin{array}{l}(2) \\
\text { task overlap }=8 / 11 \\
\text { Packer, }>5 \text { years } \\
\text { ISCO88 }=93\end{array}$ & $\begin{array}{l}(3) \\
\text { task overlap }=1 / 2 \\
\text { Finisher-repairer of textile goods, }<2 \\
\text { years } \\
\text { ISCO } 88=82\end{array}$ \\
\hline Logging activity data (number of pieces,...) & $\checkmark$ & $\checkmark$ \\
\hline Transporting the products or waste to the storage, shipping or recycling zone & $\checkmark$ & \\
\hline Providing the workstation with materials and products or checking the stock & $\checkmark$ & \\
\hline Clearing and cleaning the work area (materials, fittings,...) & $\checkmark$ & \\
\hline Packaging products according to characteristics, orders and mode of transport & $\checkmark$ & \\
\hline $\begin{array}{l}\text { Fitting, assembling and attachment of pieces. Check that the assembly has been correct (use, } \\
\text { view) }\end{array}$ & $\checkmark$ & \\
\hline $\begin{array}{l}\text { Monitoring the flow and progress of products on a production or transport line. If necessary, } \\
\text { unblock and remove elements }\end{array}$ & $\checkmark$ & \\
\hline Detect and locate visible defect and sort them accordingly (surface, color,...) & $\checkmark$ & \\
\hline \multicolumn{3}{|l|}{ Missing tasks } \\
\hline & \multicolumn{2}{|l|}{$\begin{array}{l}\text { Check the products upon } \\
\text { receipt, when completing the } \\
\text { order or upon shipment }\end{array}$} \\
\hline & \multicolumn{2}{|l|}{$\begin{array}{l}\text { Labelling the product, } \\
\text { branding and checking the } \\
\text { information (expiration } \\
\text { date,...) }\end{array}$} \\
\hline & \multicolumn{2}{|l|}{$\begin{array}{l}\text { Preventive or corrective basic } \\
\text { maintenance of machines or } \\
\text { equipment }\end{array}$} \\
\hline & & $\begin{array}{l}\text { Place design and presentation } \\
\text { materials in the article (cardboard, ...) } \\
\text { Packaging the articles }\end{array}$ \\
\hline
\end{tabular}




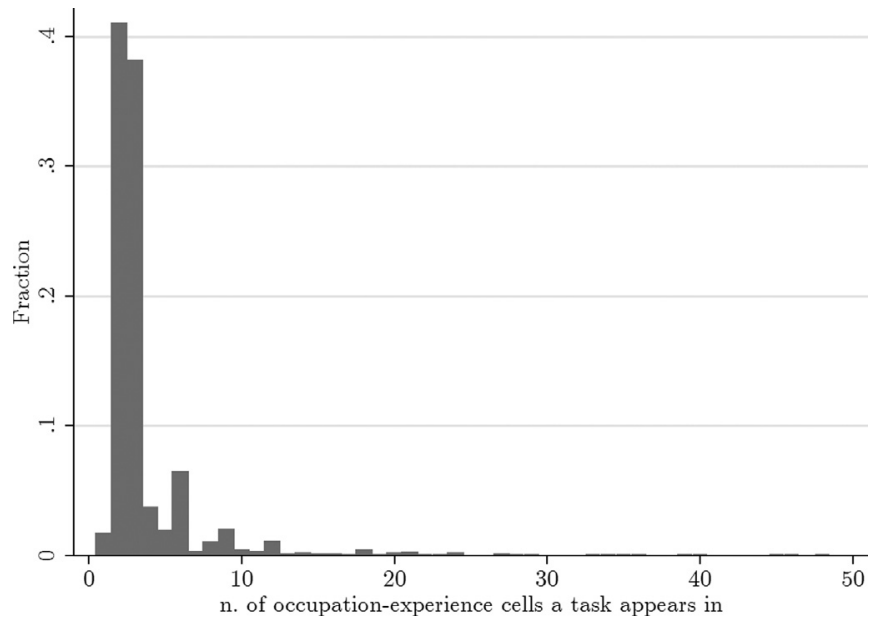

Fig. 1. Density of the Number of Jobs in which the Same Task Occurs. Source: ROME-V3. Notes: This histogram is right-censored for clarity. This discards $0.2 \%$ of the original distribution.

in our VDAB sample: "production worker with less than two years of experience". Defining task overlap for a job as the $\%$ of tasks this job has in common with another job, Columns (2) and (3) illustrate task overlap for "production workers with less than two years of experience" with two other jobs. The checkmarks show that "production workers with less than 2 years of experience" (column 1 ) have 8 of the 11 tasks in common with "packers with more than 5 years experience" (column 2), giving an overlap of $8 / 11$ or $73 \%$. Similarly, "production workers with less than 2 years of experience" (column 1) have half of the tasks in common with "finisher-repairers of textile goods with less than 2 years of experience" (column 3), giving an overlap of 50\%. Finally, Table 2 illustrates how our definition of task overlap is asymmetric between jobs. Comparing columns (1) and (2) shows that the overlap for a "packer with more than 5 years of experience" (column 2) with a job as "production workers with less than two years of experience" (column 1) is 100\%. Similarly, the overlap with "finisher-repairers of textile goods with less than 2 years of experience" (column 3) with a "production workers with less than two years of experience" (column 1) is $12.5 \%$

In ROME-V3, tasks for different experience levels are additively structured within an occupation: within the same occupation, the tasks required at higher experience levels are the sum of all tasks required at lower experience levels plus some extra tasks. For example, the job "production worker with 2 to 5 years of experience" adds some tasks to "production worker with less than 2 years of experience", and having all competencies for the former mechanically creates $100 \%$ task overlap with the latter. Because this $100 \%$ task overlap for higher with lower experience levels within the same occupation is purely mechanical, we exclude it from our definition of task overlap and, therefore, from our analyses. ${ }^{14}$

To see for which jobs there is task overlap, Fig. 2 plots a heat map illustrating the similarity of task bundles across jobs. For example, consider the point in the upper-left corner of Fig. 2 for 2-digit ISCO88 groups 11 on the $x$-axis and 93 on the $y$-axis. For each job in 11 we keep the maximum $\%$ task overlap it has with any job in 93 . We then take the average of these maxima across all jobs in 11 , and plot this average in the upper-left corner of Fig. 2. The diagonal line in Fig. 2 highlights that jobs that belong to the same 2-digit ISCO88 group are likely to have

\footnotetext{
${ }^{14}$ Note that we do not exclude the highest experience level in a different occupation for which there is $100 \%$ task overlap. Also, we do not exclude task overlap with higher experience levels within the same occupation, for which task overlap will always be less than $100 \%$ by construction of ROME-V3. We will return to these issues in Section 4.4 below.
}

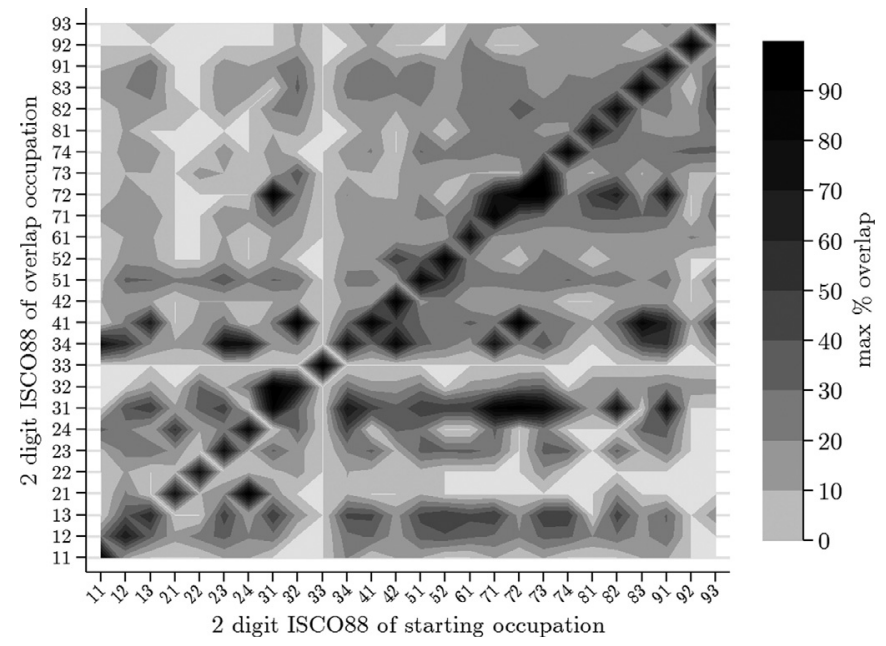

Fig. 2. Task Overlap Across Jobs. Source: ROME-V3.

similar task bundles. However, the existence of off-diagonal hotspots also shows that there is substantial task overlap across 2-digit ISCO88 occupation groups. For example, task bundles are relatively similar between occupation groups 71 to 83 . Tasks that are common across occupation groups 71 to 83 mainly involve basic maintenance and repair of machines or other equipment; the registration and dissemination of information related to production processes; and packaging and transportation of products. The figure also illustrates the asymmetry in our definition of task overlap: left and right of the diagonal are not mirror images. As will become clear below, the variation in task overlap between jobs illustrated in Fig. 2 is predictive of the probability for unemployed job seekers to find a job, i.e. labour markets overlap across jobs based on common task content.

\subsubsection{Representativeness of the VDAB sample}

For unemployed job seekers, VDAB's online job platform includes the entire population of unemployed job seekers that claim unemployment benefits, given that benefits can only be claimed conditional on registering on the platform. The VDAB further reports that for the period 2013-2014 these benefit claimants account for about 75\% of all unemployed job seekers registered on the platform. This fraction is in line with economy-wide survey data taken from the European Union Labour Force Survey (EULFS): of all Flemish unemployed job seekers registered with VDAB in 2011-2015, 72\% report receiving unemployment benefits. Moreover, of all Flemish unemployed job seekers in the EULFS, only $14 \%$ report not being registered with VDAB. What this suggests is that VDAB's online job platform captures $86 \%$ of the entire population of unemployed job seekers in Flanders.

For vacancies, VDAB's online job platform collects data from multiple sources. To check the representativeness of our vacancy sample, we compared the density across 3-digit ISCO88 occupations of vacancies in our sample with vacancies from a representative survey of Flemish firms from Belgium's Office of National Statistics. ${ }^{15}$ These densities are similar suggesting our vacancy sample is largely representative, with some oversampling of managers and associate professional jobs.

\subsection{Auxiliary data for unemployed job seekers}

Every unemployed job seeker in our VDAB sample is merged with two parts of their individual social security records. One source is used to construct (un)employment spells for the period 2010-2015. The other source contains person characteristics of each unemployed job seeker in

\footnotetext{
15 See Appendix A for further details.
} 
Table 3

Characteristics of unemployed job seekers.

\begin{tabular}{ll}
\hline & $\%$ \\
\hline Sex & \\
Male & 55.72 \\
Female & 44.28 \\
Current nationality & 0.00 \\
Belgian nationality: lifetime & 65.95 \\
Belgian nationality: acquired & 17.78 \\
Foreign, EU Nationality & 7.38 \\
Foreign, other nationality & 8.62 \\
1digit ISCED level & 0.27 \\
0-2: no diploma & \\
3-4: high school level diploma & 61.83 \\
5-6: higher education & 19.07 \\
Total & 1.66 \\
N & 100.00 \\
\hline
\end{tabular}

Source: Datawarehouse Labour Market and Social Security

our VDAB sample. We briefly discuss each of these two data sources in turn.

Firstly, for each unemployed job seeker in one of the 8 cross-sections in our VDAB sample, an (un)employment record is reconstructed from the Dimona database, which is the online application for firms to file employment records for tax purposes, for the period 2010-2015. Dimona contains the beginning and end of every contract that a job seeker agreed with any firm in half-month intervals. Consequently, for every unemployed job seeker in our VDAB sample we observe the start and end of every (un)employment spell between 2010-2015 on a bi-weekly basis. We observe a start as well as end date for $74 \%$ of all unemployment spells. Right censored unemployment spells for which a start but not an end date is observed account for the remaining $26 \%{ }^{16}$

Secondly, person characteristics of each unemployed job seeker in our VDAB sample are taken from the Datawarehouse Labour Market and Social Security, which collects individual records from different institutes within the social security system. Information about an unemployed job seeker's person characteristics is updated to the most recent year, based on when the unemployed job seeker was observed in our VDAB sample. Table 3 shows that $55 \%$ of unemployed job seekers are men and $66 \%$ have lifetime Belgian nationality. Around 15\% of unemployed job seekers did not complete high school; $63 \%$ obtain a high school level diploma; and $23 \%$ attended some form of higher education. We also observe for each unemployed job seeker in the VDAB sample the region of residence at the NUTS3 level, resulting in 24 separate regions. ${ }^{17}$

\section{Job search in labour markets with task overlap}

This section relates an unemployed job seeker's probability of finding a job to the number of vacancies and other job seekers in jobs for which she possesses all of the required task competencies, as well as in other jobs for which she only partially qualifies in terms of her task competencies because of task overlap. Such a relationship provides evidence in support of the idea that labor markets are, at least in part, organized

\footnotetext{
16 We excluded from the VDAB sample those unemployed job seekers for whom we observe an end date but not a start date of unemployment, i.e. for whom the unemployment spell is left censored. Our Dimona data show that this is the case for only $7 \%$ of all unemployed job seekers. The reason for excluding unemployed job seekers with left-censored unemployment spells is that these unemployment spells would be discarded in the duration framework used in the empirical analyses below.

17 These regions are on average 615 square kilometres in size with 290085 inhabitants on January 1, 2013. http://statbel.fgov.be/nl/statistieken.
}

along workers' task competencies. Section 4.1 outlines our empirical specification and identification, and Sections 4.2 and 4.3 present our main estimates. Finally, Section 4.4 provides some additional analyses.

\subsection{Empirical specification}

Define $i$ as an unemployed job seeker observed in our VDAB sample after pooling our 8 cross-sections. Assume that $i$ 's probability of finding employment positively depends on tightness in her labour market, defined as the number of vacancies, $\tilde{V}_{i}$, divided by the number of unemployed job seekers, $\tilde{U}_{i}$, relevant to $i$ in terms of her own task competencies. In particular, assume that the impact of (the $\log$ of) $\tilde{V}_{i}$ and $\tilde{U}_{i}$ on unemployed job seeker i's job finding probability $T_{i}$ is given by:

$T_{i}=\alpha_{1} \ln \left(\tilde{V}_{i}\right)+\alpha_{2} \ln \left(\tilde{U}_{i}\right)$

We expect that $\alpha_{1}>0$, capturing the positive externality from additional vacancies for which an unemployed job seeker (in part) qualifies in terms of her task competencies. We also expect that $\alpha_{2}<0$, capturing the negative externality from additional unemployed job seekers also (in part) qualifying for the task profile required in those vacancies. ${ }^{18}$

In Eq. (1), $i$ 's relevant vacancies, $\tilde{V}_{i}$, is a weighted sum of vacancies for which $i$ has all of the required task competencies and of vacancies for which $i$ does not have all of the required task competencies but with which there is task overlap. Similarly, $\tilde{U}_{i}$ is the weighted sum of other unemployed job seekers that fully or partially qualify for $i$ 's relevant vacancies. In particular, we define $\ln \left(\tilde{V}_{i}\right)$ and $\ln \left(\tilde{U}_{i}\right)$ as:

$$
\begin{aligned}
& \ln \left(\tilde{V}_{i}\right) \equiv \ln \left(V_{i}^{\text {all }}+\sum_{j=1}^{4} \gamma_{j} V_{i j}^{\text {some }}\right) \\
& \ln \left(\tilde{U}_{i}\right) \equiv \ln \left(U_{i}^{\text {all }}+\sum_{j=1}^{4} \beta_{j} U_{i j}^{\text {some }}\right)
\end{aligned}
$$

where $V_{i}^{\text {all }}$ is the number of vacancies and $U_{i}^{\text {all }}$ the number of other unemployed job seekers in jobs for which $i$ has all of the required task competencies, and $V_{i j}^{\text {some }}$ and $U_{i j}^{\text {some }}$ are the number of vacancies and other unemployed job seekers in jobs for which $i$ does not have all of required task competencies but with which there is some degree of task overlap. In particular, we distinguish four groups $j: j=1$ counts all vacancies and other unemployed job seekers in cells for which $i$ possesses at least $80 \%$ of the required set of task competencies; $j=2$ in cells for which there is $60 \%$ to $79 \%$ task overlap; $j=3$ in cells for which task overlap is between $30 \%$ and $59 \%$; and $j=4$ in cells for which $i$ possesses more than $0 \%$ but less than $30 \%$ of the required task competencies. ${ }^{19}$ Finally note that $\tilde{V}_{i}$ and $\tilde{U}_{i}$ are specific to each unemployed job seeker $i$. That is, labour markets and their tightness are individual specific in that they depend on an unemployed job seeker's listed job experiences when registering on the platform and their task overlap with other jobs according to ROME-V3.

Together with $\alpha_{1}$ and $\alpha_{2}$, parameters $\gamma_{j}$ and $\beta_{j}$ capture the importance for $i$ 's job finding probability of tightness in jobs for which $i$ has no listed experience but with which there is some degree of task overlap. For example, $\alpha_{1}>0$ and $\alpha_{2}<0$ but $\gamma_{j}=\beta_{j}=0$ for $j=1, \ldots, 4$ would imply that each job is insular in the sense that job seekers cannot compete for jobs for which they have no experience. In this case, task overlap across job markets would be unimportant for job seekers' unemployment durations. But if subsets of tasks and their overlap across jobs do matter, one would expect to find that $\gamma_{j}>0$ and $\beta_{j}>0$ for at least some for $j=1, \ldots, 4$. Also note that $\gamma_{j}>0$ and $\beta_{j}>0$ have an intuitive interpretation. For example, $\gamma_{1}=0.33$ would imply that the increase in $i$ 's

\footnotetext{
18 The specification in Eq. (1) follows from standard matching functions. For example, a constant-returns-to-scale Cobb-Douglas matching function can be written as Eq. (1) with $\alpha_{1}=\alpha_{2}$.

${ }^{19}$ Note that our definition of task overlap excludes jobs with which there is no task overlap. This implicitly assumes that jobs with which there is no task overlap are not part of an unemployed job seeker's labour market.
} 
tightness from one additional vacancy for which $i$ has all of the required task competencies is the same as the increase in i's tightness from three additional vacancies in jobs for which $i$ has at least $80 \%$ of the required task competencies. Similarly, $\beta_{1}=0.33$ would imply that one additional job seeker who is fully task-proficient in one of $i$ 's listed job experiences decreases i's tightness by the same amount as 3 additional job seekers in jobs for which $i$ has $80 \%$ of the required task competencies.

To consistently estimate the impact of (the $\log$ of) $\tilde{V}_{i}$ and $\tilde{U}_{i}$ on an unemployed job seeker's job finding probability, we need to account for duration dependence in unemployment spells. To do this, we use the following Weibull proportional hazard model:

$h\left(\tau_{i}\right)=k \tau_{i}^{k-1} \exp \left[T_{i}+X_{i}^{\prime} \delta\right]=k \tau_{i}^{k-1} \exp \left[\alpha_{1} \ln \left(\tilde{V}_{i}\right)+\alpha_{2} \ln \left(\tilde{U}_{i}\right)+X_{i}^{\prime} \delta\right]$

where $h\left(\tau_{i}\right)$ is the hazard function. ${ }^{20}$ For any given unemployment duration $\tau_{i}$, the hazard function gives the hazard rate, which is the conditional probability that an unemployed job seeker $i$ finds a job conditional on having been unemployed for $\tau_{i}$ periods. The term $k \tau_{i}^{k-1}$ with $k>0$ is a Weibull specification of the baseline hazard that models the impact of unemployment duration on the hazard rate. If $0<k<1$, an increase in unemployment duration decreases the hazard rate and duration dependence is negative. If $k>1$, an increase in unemployment duration increases the hazard rate and duration dependence is positive.

Parameters $\alpha_{1}$ and $\alpha_{2}$, capturing search externalities, result in a proportional shift in the hazard function $h\left(\tau_{i}\right)$ for a proportional change in vacancies and unemployed job seekers respectively: $\partial \ln \left(h\left(\tau_{i}\right)\right) / \partial \ln \left(\tilde{V}_{i}\right)=$ $\alpha_{1}$ and $\partial \ln \left(h\left(\tau_{i}\right)\right) / \partial \ln \left(\tilde{U}_{i}\right)=\alpha_{2}$. For example, with $\alpha_{1}>0$ and $\alpha_{2}<0$, an increase in $\ln \left(\tilde{V}_{i}\right)$ relative to $\ln \left(\tilde{U}_{i}\right)$ is expected to shift the hazard function up because labour market tightness is higher. Similarly, lower labour market tightness is expected to shift the hazard function down.

The vector $X_{i}$ contains a constant and a number of controls that could be important in job search, i.e. person characteristics other than an unemployed job seeker's labour market tightness that could also shift the hazard function up or down. Controls in $X_{i}$ will include unemployed job seekers' preferences to work only full-time, only part-time, or be open to both, taken from the VDAB sample. For example, Diamond and Sahin (2016) use US data to show that a worker's preference for a parttime or full-time employment is predictive of finding a new job. ${ }^{21}$ Vector $X_{i}$ will also include gender, nationality, and educational attainment of unemployed job seekers, taken from Datawarehouse Labour Market and Social Security as discussed above. Finally, some of our estimates will include location (i.e. 3-digit NUTS region of residence of unemployed job seekers taken from Datawarehouse Labour Market and Social Security) and time fixed effects to control for endogenous shocks that are location and time specific.

For our analyses to be informative about unemployment durations, the survival function corresponding to the estimated hazard function has to be specified. To see how this is done, consider a hazard and survival function that are both related to the same probability density function (dropping subscripts $i$ for simplicity) $f(\tau)$ : the probability of finding a job $\tau$ periods after becoming unemployed. The survival function then is the reverse cumulative distribution function of

\footnotetext{
${ }^{20}$ Eq. (3) will be estimated using a maximum likelihood specification that accounts for right-censored unemployment spells in our data. For an overview of duration modelling, see Van den Berg (2001).

21 An individual's preference for taking up part-time or full-time work is collected when an unemployed job seeker registers on the platform. This could be when the platform was introduced to unemployed job seekers in 2012, or when a worker became unemployed sometime after 2012. Important for our analyses, an individual's preference for taking up part-time or full-time work may be endogenous to her job market tightness. However, our results below show that omitting or including this variable as a control in our analyses does not affect point estimates for job market tightness. Although not reported here, we also find that an individual's preference for part-time or full-time work is accurately predicted by individual characteristics, and that small prediction errors do not systematically vary with labour market tightness.
}

$f(\tau): S(\tau)=1-F(\tau)$, with $F(\tau)=\int_{0}^{t} f(\tau) d \tau$. It measures the cumulative probability of staying unemployed for $\tau$ periods. The hazard rate is then defined as $h(\tau)=f(\tau) / S(\tau)$. It is the probability of finding a job after $\tau$ periods, conditional on not having found one earlier. Also note that, by definition, $f(\tau)=d F(\tau) / d \tau=d(1-S(\tau)) / d \tau=-d S(\tau) / d \tau$. This implies that $h(\tau)=f(\tau) / S(\tau)=(-d S(\tau) / d \tau) / S(\tau)$ or that $d \ln S(\tau) / d \tau=-h(\tau)$. Integrating both sides over $\tau$ and taking the exponential then gives: $S(\tau)=\exp \left[\int_{0}^{\infty}-h(\tau) d \tau\right]$.

Using the Weibull proportional hazard model from Eq. (3) above, the corresponding survival function can thus be written as:

$S\left(\tau_{i}\right)=\exp \left[-\tau_{i}^{k} \exp \left[T_{i}+X_{i}^{\prime} \delta\right]\right]=\exp \left[-\tau_{i}^{k} \exp \left[\alpha_{1} \ln \left(\tilde{V}_{i}\right)+\alpha_{2} \ln \left(\tilde{U}_{i}\right)+X_{i}^{\prime} \delta\right]\right]$

The survival function is decreasing in $\tau_{i}$ given that $k>0$. An increase in labour market tightness shifts the survival function down, whereas a decrease in labour market tightness shifts it up. Finally note that unemployed job seeker i's expected unemployment duration is given by $E\left[S\left(\tau_{i}\right)\right]=\int_{0}^{\infty} S\left(\tau_{i}\right) d \tau_{i}$. Consequently, an increase in i's labour market tightness not only shifts the survival function down but also reduces $i$ 's expected unemployment duration. Similarly, a decrease in i's labour market tightness increases i's expected unemployment duration. ${ }^{22}$

In sum, observing $\tau_{i}, \tilde{V}_{i}, \tilde{U}_{i}$, and $X_{i}$ for each unemployed job seeker $i$ observed in one of the 8 cross-sections in our VDAB sample allows us to estimate parameters $k, \alpha_{1}, \alpha_{2}, \delta$, and $\gamma_{j}$ and $\beta_{j}$ for $j=1, \ldots, 4$ using Eq. (3). These estimates will be informative about whether or not there exist markets for jobs and about the importance of task overlap across jobs.

\subsection{Estimates without allowing for task overlap}

Using our data discussed in Section 3, this subsection first presents estimates of $\alpha_{1}$ and $\alpha_{2}$ assuming that $\gamma_{j}=\beta_{j}=0$ for $j=1, \ldots, 4$ in Eq. (2). Therefore, this subsection presents baseline estimates assuming that there is no task overlap across jobs in an unemployed job seeker's labour market. Eq. (1) then simplifies to the following expression:

$T_{i}=\alpha_{1} \ln \left(V_{i}^{\text {all }}\right)+\alpha_{2} \ln \left(U_{i}^{\text {all }}\right)$

Substituting the right-hand side of Eq. (5) into (3) and using $\tau_{i}, V_{i}^{\text {all }}$, $U_{i}^{\text {all }}$ and $X_{i}$ from our data, parameters $\alpha_{1}, \alpha_{2}, \delta$ and $k$ can be estimated. Table 4 reports estimates of $\alpha_{1}, \alpha_{2}$, and $\delta$ as odds ratios: estimates $\exp \left(\hat{\alpha_{1}}\right), \exp \left(\hat{\alpha_{2}}\right)$ and $\exp (\hat{\delta})$ are shown, which should be interpreted relative to unity. ${ }^{23}$

The first and second rows of Table 4 report estimates of $\exp \left(\hat{\alpha_{1}}\right)$ and $\exp \left(\hat{\alpha_{2}}\right)$ respectively. Column (1) excludes $X_{i}$ from the analysis, finding that $\exp \left(\hat{\alpha_{1}}\right)=1.126$. What this means is that a 1 log-point increase in the number of vacancies increases the hazard rate by $12.6 \%$. Conversely, a 1 log-point increase in the number of other unemployed job seekers decreases the hazard rate by $7.5 \%$, since $\exp \left(\hat{\alpha_{2}}\right)=0.925$. In sum, these estimates suggest that $\alpha_{1}>0$ and $\alpha_{2}<0$ and that labour markets are in part organized along bundles of tasks captured by our detailed classification of jobs for which workers fully qualify in terms of their task competencies. ${ }^{24}$ As is well documented in literature (e.g. see van den Berg

\footnotetext{
${ }^{22}$ In contrast to the hazard rate, the change in unemployment duration due to a proportional change in vacancies or unemployed job seekers is not independent of $\tau_{i}$. For example, the proportional change in unemployment duration following a proportional change in vacancies is given by $\partial \ln \left(S\left(\tau_{i}\right)\right) / \partial \ln \left(\tilde{V}_{i}\right)=-\tau_{i}^{k} \exp \left[T_{i}+\right.$ $\left.X_{i}^{\prime} \delta\right] \alpha_{1}$ which depends on $\tau_{i}$.

${ }^{23}$ The number of observations reported at the bottom of Table 4 are somewhat lower than the number of possible unemployment spells in our VDAB sample, given by 139,944 (an average of 17,493 unemployed job seekers per cross section $\times 8$ cross-sections). This is because the analyses necessarily exclude unemployed job seekers for whom there are no vacancies in their listed job experiences and for whom personal characteristics listed in Table 3 are missing.

${ }^{24}$ The Schoenfeld residuals test examines the assumption that the impact of tightness on the hazard rate is independent of $\tau_{i}$. Results not reported here reveal
} 
Table 4

Explaining job finding probabilities without task overlap across jobs.

\begin{tabular}{|c|c|c|c|c|}
\hline Variables & $\begin{array}{l}\text { (1) } \\
\text { odds ratio }\end{array}$ & $\begin{array}{l}\text { (2) } \\
\text { odds ratio }\end{array}$ & $\begin{array}{l}\text { (3) } \\
\text { odds ratio }\end{array}$ & $\begin{array}{l}\text { (4) } \\
\text { odds ratio }\end{array}$ \\
\hline $\ln V_{i}^{\text {all }}$ & $\begin{array}{l}1.126^{* * *} \\
(0.004)\end{array}$ & $\begin{array}{l}1.134^{* * * *} \\
(0.004)\end{array}$ & $\begin{array}{l}1.112^{* * *} \\
(0.004)\end{array}$ & $\begin{array}{l}1.122^{* * *} \\
(0.004)\end{array}$ \\
\hline $\ln U_{i}^{a l l}$ & $\begin{array}{l}0.925^{* * *} \\
(0.003)\end{array}$ & $\begin{array}{l}0.925^{* * *} \\
(0.003)\end{array}$ & $\begin{array}{l}0.943^{* * *} \\
(0.004)\end{array}$ & $\begin{array}{l}0.940^{* * * *} \\
(0.004)\end{array}$ \\
\hline Female & & $\begin{array}{l}0.971^{* * * *} \\
(0.009)\end{array}$ & & $\begin{array}{l}0.962^{* * * *} \\
(0.009)\end{array}$ \\
\hline Belgian nationality: acquired & & $\begin{array}{l}0.888^{* * * *} \\
(0.010)\end{array}$ & & $\begin{array}{l}0.906^{* * * *} \\
(0.011)\end{array}$ \\
\hline Foreign, EU nationality & & $\begin{array}{l}0.822^{* * *} \\
(0.014)\end{array}$ & & $\begin{array}{l}0.845^{* * *} \\
(0.015)\end{array}$ \\
\hline Foreign, other nationality & & $\begin{array}{l}0.915^{* * * *} \\
(0.014)\end{array}$ & & $\begin{array}{l}0.960^{* * * *} \\
(0.015)\end{array}$ \\
\hline Part-time & & $\begin{array}{l}0.757^{* * * *} \\
(0.012)\end{array}$ & & $\begin{array}{l}0.768^{* * * *} \\
(0.013)\end{array}$ \\
\hline Part-time or full-time & & $\begin{array}{l}0.915^{* * *} \\
(0.009)\end{array}$ & & $\begin{array}{l}0.912^{* * *} \\
(0.009)\end{array}$ \\
\hline High School & & & $\begin{array}{l}1.253^{* * *} \\
(0.016)\end{array}$ & $\begin{array}{l}1.218^{* * *} \\
(0.016)\end{array}$ \\
\hline College & & & $\begin{array}{l}1.335^{* * * *} \\
(0.020)\end{array}$ & $\begin{array}{l}1.297^{* * * *} \\
(0.020)\end{array}$ \\
\hline Constant & $\begin{array}{l}0.433^{* * * *} \\
(0.007)\end{array}$ & $\begin{array}{l}0.398^{* * * *} \\
(0.011)\end{array}$ & $\begin{array}{l}0.334^{* * * *} \\
(0.001)\end{array}$ & $\begin{array}{l}0.412^{* * *} \\
(0.010)\end{array}$ \\
\hline Observations & 133,440 & 130,928 & 129,193 & 126,766 \\
\hline Location FE & NO & YES & NO & YES \\
\hline Time FE & NO & YES & NO & YES \\
\hline Weibull $k$ & 0.403 & 0.412 & 0.403 & 0.412 \\
\hline
\end{tabular}

Source: VDAB: Mijn Loopbaan; Dimona; Datawarehouse Labour Market and Social Security. Notes: Standard errors in parentheses. ${ }^{*},{ }^{* *}$ and ${ }^{* * *}$ stand for 10,5 and $1 \%$ statistical significance respectively. Omitted categories for nationality, working regime preferences and education are lifetime Belgian national, full-time work and less than high-school qualification respectively.

and van Ours 1996 and Kroft et al. 2013), the estimate of 0.403 for $k$ at the bottom of column (1) suggests that there is negative duration dependence.

Figs. 3 and 4 show what these estimates imply for standard deviation changes in log vacancies and $\log$ job seekers, which equal 1.6 and 1.7 log-points respectively. In panels (a) of Figs. 3 and 4, the hazard function shifts up proportionally with an increase in vacancies and down with an increase in job seekers. Panels (b) of Figs. 3 and 4 show the shift in the survival function for the same standard deviation changes in $\log$ vacancies and job seekers. For example, our estimates predict that the expected unemployment duration decreases by 11 weeks from an average of 30 weeks when the number of vacancies in a job increases by a standard deviation from the mean.

Column (2) of Table 4 adds some of the personal characteristics discussed in Table 3 as controls in $X_{i}$ to the analysis. Estimates of $\alpha_{1}, \alpha_{2}$, and $k$ are almost identical to those of column (1). Moreover, the coefficients for the controls themselves are as expected: women have significantly lower hazard rates than men; relative to unemployed job seekers who have lifetime Belgian nationality, those with acquired Belgian or those with foreign nationality have significantly lower hazard rates; and looking for part-time rather than full-time employment is associated with lower hazard rates. The inclusion of location and time fixed-effects rules out that our point estimates are contaminated by common regional or

that there is some non-proportionality in the effect of market tightness: The shift in the hazard function for variation in vacancies and job seekers is slightly larger for larger values of $\tau_{i}$. One way to explicitly account for this in our analysis is by adding interactions between variables $\ln \left(V_{i}^{\text {all }}\right), \ln \left(U_{i}^{\text {all }}\right)$ and $\tau_{i}$. Estimated coefficients for these interaction terms indicate that the impact of tightness on the hazard rate increases with $\tau_{i}$ indeed, but also that this impact is small and does not qualitatively change our results. time specific shocks - see Borowczyk-Martins et al. (2013) for further discussion of the importance of such shocks.

Finally, to ensure that our specification of jobs is not mainly capturing variation in unemployed job seekers' educational attainments, columns (3) and (4) repeat the analyses in columns (1) and (2) while adding education as a control. Estimates for $\alpha_{1}$ and $\alpha_{2}$ decrease somewhat, but remain statistically significant. The coefficients on the educational controls themselves show that, compared to job seekers with no high school qualifications, having a high school degree or having obtained tertiary education shifts the hazard function upwards. That is, all else equal, unemployed job seekers with higher educational attainments are expected to have shorter unemployment durations.

\subsection{Estimates allowing for task overlap}

The previous subsection showed the importance of labour market tightness in our detailed classification of jobs for understanding unemployment durations. However, in setting $\gamma_{j}=\beta_{j}=0$ for $j=1, \ldots, 4$ in Eq. (2), it assumed that jobs are entirely insular, despite the significant degree of task overlap shown in Figs. 1 and 2. If job markets overlap because of task similarities, one would expect that $\gamma_{j}>0$ and $\beta_{j}>0$ for at least some $j=1, \ldots, 4$. Therefore, this subsection provides estimates of $\alpha_{1}, \alpha_{2}, \gamma_{j}$ and $\beta_{j}$ while not restricting the analysis to $\gamma_{j}=\beta_{j}=0$ for all $j=1, \ldots, 4$.

However, if $\gamma_{j}$ and $\beta_{j}$ are not all zero for $j=1, \ldots, 4$, Eq. (1) is no longer linear in parameters $\alpha_{1}$ and $\gamma_{j}$ or in $\alpha_{2}$ and $\beta_{j}$, such that their values can no longer be estimated using Eq. (3). To solve this problem, first define $V_{i} \equiv V_{i}^{\text {all }}+V_{i 1}^{\text {some }}$ as the count of vacancies in individual $i$ 's listed job experiences and other jobs with which there is at least $80 \%$ task overlap. Similarly, define $U_{i} \equiv U_{i}^{\text {all }}+U_{i 1}^{\text {some }}$ as a headcount of unemployed job seekers in individual $i$ 's listed job experiences and other jobs with at least $80 \%$ task overlap. Next approximate $T_{i}+X_{i}^{\prime} \delta$ in Eq. (3) by 
(a) Hazard Function

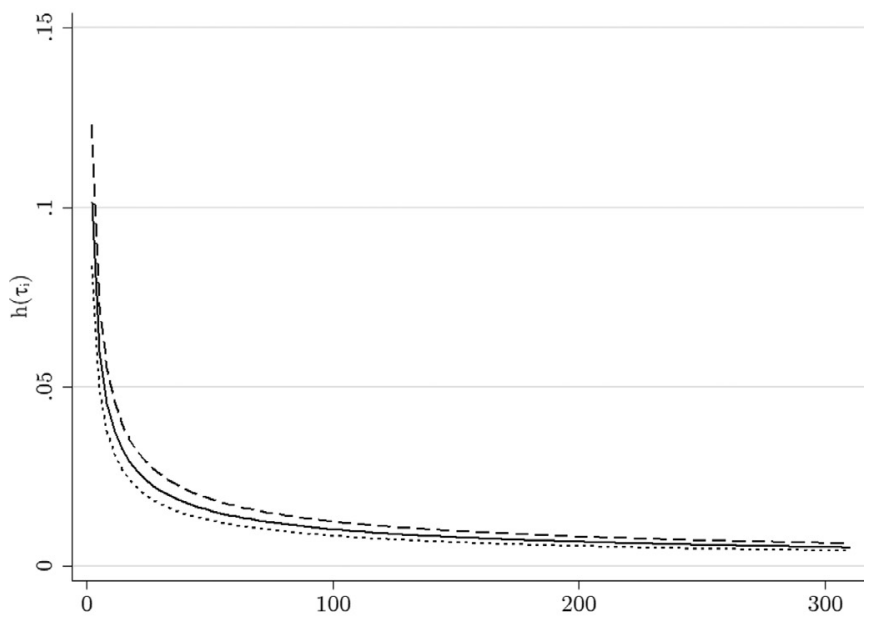

(b) Survival Function

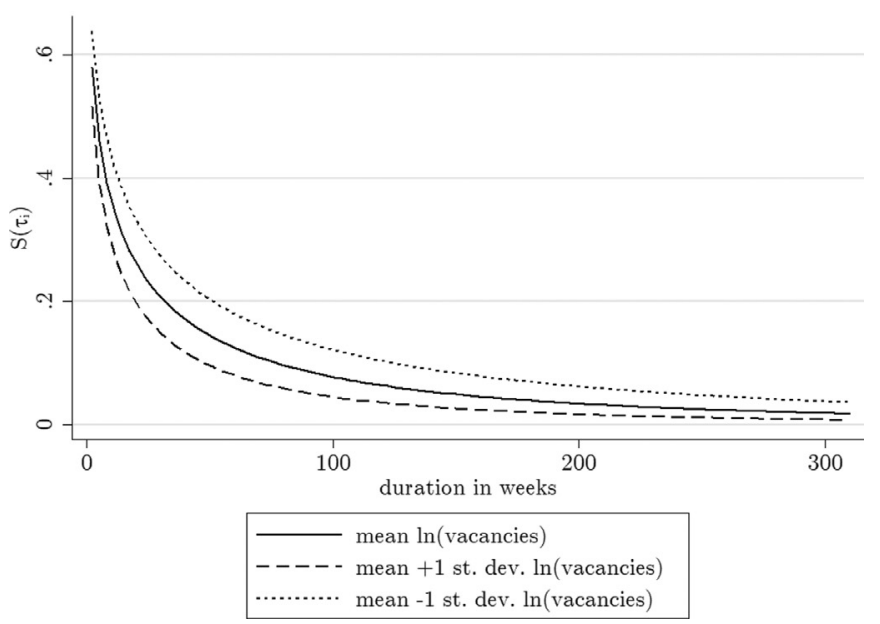

Fig. 3. Hazard and Survival Functions for Different Levels of Vacancies. Source: VDAB: Mijn Loopbaan; Dimona; Datawarehouse Labour Market and Social Security. Notes: The level of unemployed job seekers is kept constant at the mean.

the following linearisation: ${ }^{25}$

$T_{i}+X_{i}^{\prime} \delta \approx \alpha_{1} \ln \left(V_{i}\right)+\alpha_{2} \ln \left(U_{i}\right)+\alpha_{1} \frac{1-\gamma_{1}}{\gamma_{1}} \frac{V_{i}^{\text {all }}}{V_{i}}+\alpha_{2} \frac{1-\beta_{1}}{\beta_{1}} \frac{U_{i}^{\text {all }}}{U_{i}}+X_{i}^{\prime} \delta$

$+\alpha_{1} \sum_{j=2}^{4} \frac{\gamma_{j}}{\gamma_{1}} \frac{V_{i j}^{\text {some }}}{V_{i}}+\alpha_{2} \sum_{j=2}^{4} \frac{\beta_{j}}{\beta_{1}} \frac{U_{i j}^{\text {some }}}{U_{i}}$

Substituting the right hand side of Eq. (6) into (3), the estimated coefficients on $\ln \left(V_{i}\right)$ and $\ln \left(U_{i}\right)$ are point estimates of $\alpha_{1}$ and $\alpha_{2}$ respectively and, together with estimated coefficients on $V_{i}^{\text {all }} / V_{i}$ and $U_{i}^{\text {all }} / U_{i}$, allow us to back out estimates for $\gamma_{1}$ and $\beta_{1}$. Given these point estimates for $\alpha_{1}$ and $\gamma_{1}$, one can then compute a value for $\gamma_{j}$ from the estimated coefficient on $V_{i j}^{\text {some }} / V_{i}$ for $j=2,3,4$. Similarly, having an estimate for $\alpha_{2}$ and $\beta_{1}$ allows us to calculate a value for $\beta_{j}$ from the estimated coefficient on $U_{i j}^{\text {some }} / U_{i}$ for $j=2,3,4$.

The first two rows of Table 5 report $\exp \left(\hat{\alpha_{1}}\right)$ and $\exp \left(\hat{\alpha_{2}}\right)$, respectively. These estimates are qualitatively similar to those in Table 4. For example, column (4) shows that $\exp \left(\hat{\alpha_{1}}\right)=1.114$ and $\exp \left(\hat{\alpha_{2}}\right)=0.945$ in the model with a full set of controls. The point estimate on $V_{i}^{\text {all }} / V_{i}$ is 1.251, larger than the estimate for $\exp \left(\hat{\alpha_{1}}\right)$, which implies $0<\gamma_{1}<0.5$. Similarly, the estimated coefficient on $U_{i}^{\text {all }} / U_{i}$ is 0.805 , which is further below unity than the estimate for $\exp \left(\hat{\alpha_{2}}\right)$, meaning that $0<\beta_{1}<0.5$. Esti-

\footnotetext{
${ }^{25}$ See Appendix B for details.
}

(a) Hazard Function

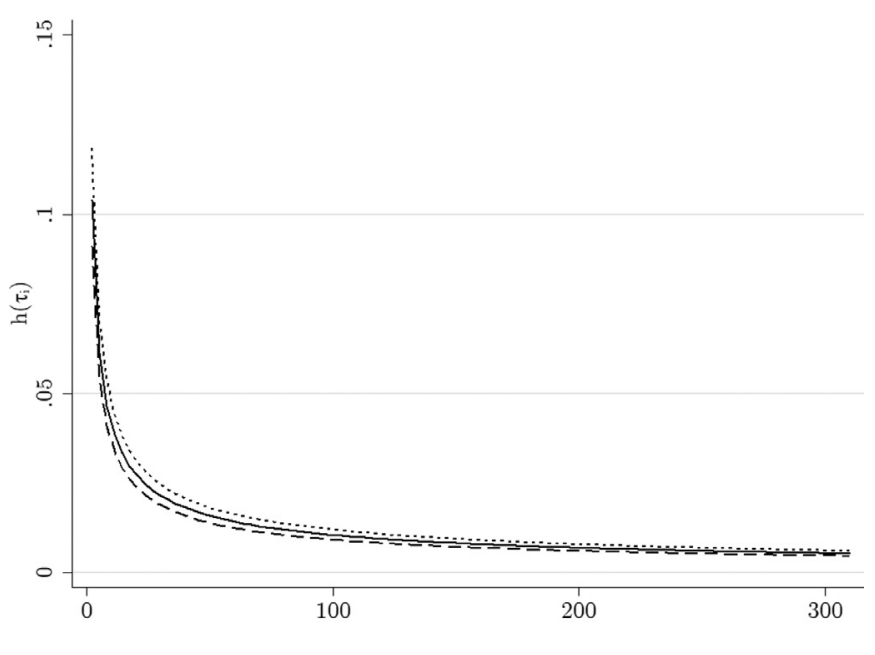

(b) Survival Function

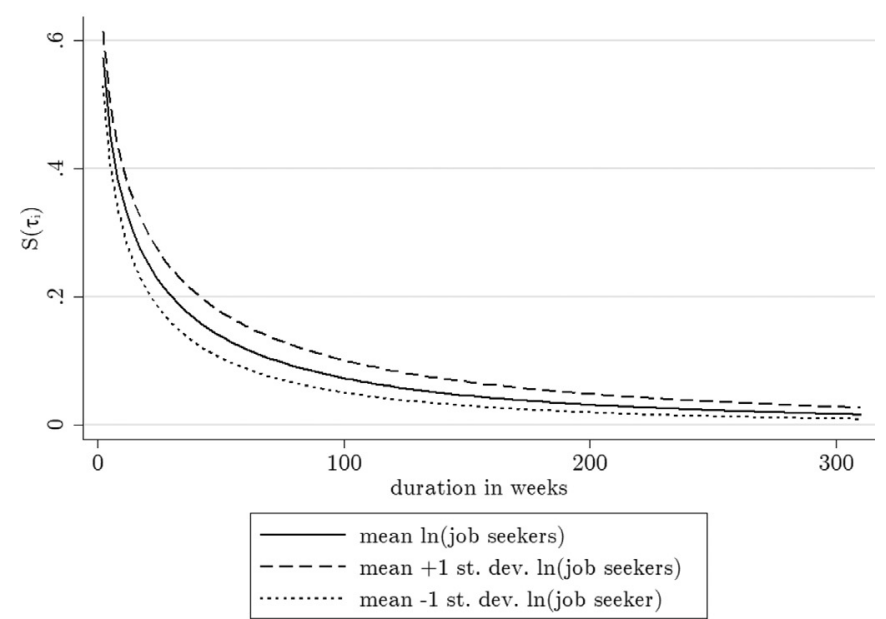

Fig. 4. Hazard and Survival Functions for Different Levels of Unemployed Job Seekers. Source: VDAB: Mijn Loopbaan; Dimona; Datawarehouse Labour Market and Social Security. Notes: The level of vacancies is kept constant at the mean.

mated coefficients on $V_{i j}^{\text {some }} / V_{i}$ and $U_{i j}^{\text {some }} / U_{i}$ are unity, suggesting that $\gamma_{j}=\beta_{j}=0$ for $j=2,3,4$.

To summarize our findings, Table 6 reports imputed values for $\gamma_{j}$ and $\beta_{j}$, where the column numbers correspond to the column numbers from Table 5. The first row of Table 6 shows that $\gamma_{1} \approx 0.33$ and $\beta_{1} \approx 0.25$. The finding that $\gamma_{1}$ and $\beta_{1}$ are strictly positive implies that tightness in jobs for which unemployed job seekers have no listed experience but for which they possess a substantial (at least 80\%) subset of the required task competencies is also predictive of finding a job. Given that a job consists of 7 different tasks on average, this means that unemployed job seekers can fail to qualify for 1 or 2 of the required tasks and still be matched to those jobs. However, also note that the impact of tightness in those jobs is only a third (for vacancies) or quarter (for other unemployed job seekers) of what it is in jobs for which unemployed job seekers have listed experience. For example, the increase in an unemployed job seeker's hazard rate would be the same for one additional vacancy for which she has experience as for three additional vacancies in a job for which she has no experience but for which she has at least $80 \%$ of the required task competencies. ${ }^{26}$

\footnotetext{
${ }^{26}$ Our choice of $j=1$ set at a cut-off of $80 \%$ task overlap is discretionary.
} Therefore, we also estimated $\gamma_{1}$ and $\beta_{1}$ choosing different cut-offs between $75 \%$ 
Table 5

Explaining job finding probabilities with task overlap across jobs.

\begin{tabular}{|c|c|c|c|c|}
\hline Variables & $\begin{array}{l}\text { (1) } \\
\text { odds ratio }\end{array}$ & $\begin{array}{l}\text { (2) } \\
\text { odds ratio }\end{array}$ & $\begin{array}{l}\text { (3) } \\
\text { odds ratio }\end{array}$ & $\begin{array}{l}\text { (4) } \\
\text { odds ratio }\end{array}$ \\
\hline $\ln V_{i}$ & $\begin{array}{l}1.120^{* * * *} \\
(0.005)\end{array}$ & $\begin{array}{l}1.128^{* * *} \\
(0.005)\end{array}$ & $\begin{array}{l}1.103^{* * *} \\
(0.005)\end{array}$ & $\begin{array}{l}1.114^{* * *} \\
(0.005)\end{array}$ \\
\hline $\ln U_{i}$ & $\begin{array}{l}0.927^{* * *} \\
(0.004)\end{array}$ & $\begin{array}{l}0.927^{* * *} \\
(0.004)\end{array}$ & $\begin{array}{l}0.948^{* * *} \\
(0.004)\end{array}$ & $\begin{array}{l}0.945^{* * *} \\
(0.004)\end{array}$ \\
\hline$V_{i}^{\text {all }} / V_{i}$ & $\begin{array}{l}1.235^{* * *} \\
(0.031)\end{array}$ & $\begin{array}{l}1.266^{* * *} \\
(0.032)\end{array}$ & $\begin{array}{l}1.218^{* * *} \\
(0.031)\end{array}$ & $\begin{array}{l}1.251^{* * *} \\
(0.033)\end{array}$ \\
\hline$U_{i}^{\text {all }} / U_{i}$ & $\begin{array}{l}0.830^{* * * *} \\
(0.020)\end{array}$ & $\begin{array}{l}0.814^{* * *} \\
(0.020)\end{array}$ & $\begin{array}{l}0.817^{* * *} \\
(0.020)\end{array}$ & $\begin{array}{l}0.805^{* * *} \\
(0.020)\end{array}$ \\
\hline$V_{i 2}^{\text {some }} / V_{i}$ & $\begin{array}{l}1.007 \\
(0.005)\end{array}$ & $\begin{array}{l}1.006 \\
(0.006)\end{array}$ & $\begin{array}{l}1.002 \\
(0.005)\end{array}$ & $\begin{array}{l}1.003 \\
(0.006)\end{array}$ \\
\hline$V_{i 3}^{\text {some }} / V_{i}$ & $\begin{array}{l}1.000 \\
(0.000)\end{array}$ & $\begin{array}{l}1.001 \\
(0.000)\end{array}$ & $\begin{array}{l}1.000 \\
(0.000)\end{array}$ & $\begin{array}{l}1.000 \\
(0.000)\end{array}$ \\
\hline$V_{i 4}^{\text {some }} / V_{i}$ & $\begin{array}{l}1.000^{* *} \\
(0.000)\end{array}$ & $\begin{array}{l}1.000^{*} \\
(0.000)\end{array}$ & $\begin{array}{l}1.000^{* * *} \\
(0.000)\end{array}$ & $\begin{array}{l}1.000^{*} \\
(0.000)\end{array}$ \\
\hline$U_{i 2}^{\text {some }} / U_{i}$ & $\begin{array}{l}1.014 \\
(0.022)\end{array}$ & $\begin{array}{l}1.015 \\
(0.022)\end{array}$ & $\begin{array}{l}1.041^{*} \\
(0.023)\end{array}$ & $\begin{array}{l}1.036 \\
(0.023)\end{array}$ \\
\hline$U_{i 3}^{\text {some }} / U_{i}$ & $\begin{array}{l}1.002 \\
(0.003)\end{array}$ & $\begin{array}{l}1.002 \\
(0.003)\end{array}$ & $\begin{array}{l}1.004 \\
(0.003)\end{array}$ & $\begin{array}{l}1.004 \\
(0.003)\end{array}$ \\
\hline$U_{i 4}^{\text {some }} / U_{i}$ & $\begin{array}{l}1.000 \\
(0.000)\end{array}$ & $\begin{array}{l}0.999^{*} \\
(0.000)\end{array}$ & $\begin{array}{l}1.000 \\
(0.000)\end{array}$ & $\begin{array}{l}1.000 \\
(0.000)\end{array}$ \\
\hline Female & & $\begin{array}{l}0.971^{* * *} \\
(0.009)\end{array}$ & & $\begin{array}{l}0.962^{* * *} \\
(0.009)\end{array}$ \\
\hline Belgian nationality: acquired & & $\begin{array}{l}0.886^{* * * *} \\
(0.010)\end{array}$ & & $\begin{array}{l}0.903^{* * *} \\
(0.011)\end{array}$ \\
\hline Foreign, EU nationality & & $\begin{array}{l}0.821^{* * *} \\
(0.014)\end{array}$ & & $\begin{array}{l}0.843^{* * *} \\
(0.015)\end{array}$ \\
\hline Foreign, other nationality & & $\begin{array}{l}0.911^{* * *} \\
(0.014)\end{array}$ & & $\begin{array}{l}0.955^{* * *} \\
(0.015)\end{array}$ \\
\hline Part-time & & $\begin{array}{l}0.759^{* * *} \\
(0.012)\end{array}$ & & $\begin{array}{l}0.770^{* * *} \\
(0.013)\end{array}$ \\
\hline Part-time or full-time & & $\begin{array}{l}0.917^{* * * *} \\
(0.009)\end{array}$ & & $\begin{array}{l}0.913^{* * * *} \\
(0.009)\end{array}$ \\
\hline High School & & & $\begin{array}{l}1.255^{* * *} \\
(0.016)\end{array}$ & $\begin{array}{l}1.219^{* * *} \\
(0.016)\end{array}$ \\
\hline College & & & $\begin{array}{l}1.349^{* * *} \\
(0.021)\end{array}$ & $\begin{array}{l}1.309^{* * *} \\
(0.021)\end{array}$ \\
\hline Constant & $\begin{array}{l}0.420^{* * *} \\
(0.001)\end{array}$ & $\begin{array}{l}0.385^{* * *} \\
(0.014)\end{array}$ & $\begin{array}{l}0.324^{* * *} \\
(0.001)\end{array}$ & $\begin{array}{l}0.411^{* * * *} \\
(0.012)\end{array}$ \\
\hline Observations & 134,793 & 132,257 & 130,428 & 127,979 \\
\hline Location FE & NO & YES & NO & YES \\
\hline Time FE & NO & YES & NO & YES \\
\hline Weibull $k$ & 0.403 & 0.411 & 0.403 & 0.411 \\
\hline
\end{tabular}

Source: VDAB: Mijn Loopbaan; Dimona; Datawarehouse Labour Market and Social Security. Notes: Standard errors in parentheses. ${ }^{*},{ }^{* *}$ and ${ }^{* * *}$ stand for 10,5 and $1 \%$ statistical significance respectively. Omitted categories for nationality, working regime preferences and education are lifetime Belgian national, full-time work and less than high-school qualification respectively.

The second to fourth rows of Table 6 also shows that $\gamma_{j}=\beta_{j} \approx 0$ for $j=2,3,4$. On the one hand, lower estimates of $\gamma_{j}$ and $\beta_{j}$ for $j=2,3,4$ are intuitive as the importance of tightness in more distant jobs is expected to be lower. On the other hand, $\gamma_{j}=\beta_{j}=0$ for $j=2,3,4$ suggests that jobs for which unemployed job seekers do not possess a substantial (less than $80 \%$ or fewer than 5 out of 7 tasks) subset of the required task competencies are entirely irrelevant. The next subsection first reports a number of robustness checks.

\subsection{Additional analyses}

\subsubsection{Switching to occupations with perfect task overlap}

In the analyses above, jobs were defined as detailed occupationexperience cells and their task contents, taken from ROME-V3. Also, because ROME-V3 mechanically adds tasks to higher experience levels

and $85 \%$. For $\gamma_{1}$, we found similar estimates. For $\beta_{1}$, we found that $\hat{\beta}_{1}$ increased from 0.26 to 0.31 as the cut-off increased from $75 \%$ to $85 \%$, suggesting a more monotonic declining relationship between job finding probabilities and job distance in terms of task content. Results are shown in Appendix C. within an occupation, our definition of task overlap excluded $100 \%$ task overlap with lower experience levels within the same occupation. However, our definition of task overlap did not exclude the highest experience level in a different occupation for which there is $100 \%$ task overlap. What this implied was that, in the analyses above, an unemployed job seeker's job market excluded lower experience levels in those occupations that were part of her listed job experiences, but included the highest experience level in other occupations with which there is perfect task overlap. This is not uncommon in our sample: up to $80 \%$ of all unemployed job seekers that we observe has perfect task overlap with at least one occupation for which she has no listed experience.

The intuition for including jobs in other occupations with which there is perfect task overlap is that these jobs could be more distant (relative to lower experience levels in the same occupations that are part of an unemployed job seeker's listed experiences) because the unemployed job seeker has no listed experience in these occupations. This reasoning is in line with (Cortes and Gallipoli, 2018), who argue that the cost of switching occupations consists of an overall adjustment cost irrespective of the change in task contents as well as of adjustment costs related to the change in task content. This subsection provides additional support 
Table 6

The importance of task overlap in the probability of finding a job.

\begin{tabular}{lllllllll}
\hline & \multicolumn{9}{c}{$\gamma$} & & \multicolumn{3}{c}{$\beta$} & \\
$j=1: 80-100 \%$ & $(1)$ & $(2)$ & $(3)$ & $(4)$ & $(1)$ & $(2)$ & $(3)$ & $(4)$ \\
& $0.3501^{* * *}$ & $0.3388^{* * *}$ & $0.3318^{* * *}$ & $0.3253^{* * *}$ & $0.2907^{* * *}$ & $0.2695^{* * *}$ & $0.2088^{* * *}$ & $0.2078^{* * *}$ \\
& $(0.0284)$ & $(0.0255)$ & $(0.0304)$ & $(0.0270)$ & $(0.0281)$ & $(0.0248)$ & $(0.0235)$ & $(0.0221)$ \\
$j=2: 60-79 \%$ & 0.0217 & 0.0177 & 0.0072 & 0.0082 & -0.0540 & -0.0525 & $-0.1562^{*}$ & -0.1293 \\
& $(0.0163)$ & $(0.0156)$ & $(0.0185)$ & $(0.0170)$ & $(0.0815)$ & $(0.0782)$ & $(0.0866)$ & $(0.0822)$ \\
$j=3: 30-59 \%$ & 0.0013 & 0.0015 & 0.0014 & 0.0014 & -0.0082 & -0.0085 & -0.0156 & -0.0149 \\
& $(0.0013)$ & $(0.0012)$ & $(0.0014)$ & $(0.0013)$ & $(0.0102)$ & $(0.0095)$ & $(0.0105)$ & $(0.0098)$ \\
$j=4: 1-29 \%$ & $-0.0006^{* *}$ & $-0.0005^{*}$ & $-0.0008^{* *}$ & $-0.0005^{*}$ & 0.0017 & $0.0020^{*}$ & 0.0011 & 0.0016 \\
& $(0.0003)$ & $(0.0003)$ & $(0.0003)$ & $(0.0003)$ & $(0.0011)$ & $(0.0011)$ & $(0.0011)$ & $(0.0011)$ \\
\hline
\end{tabular}

Source: VDAB: Mijn Loopbaan; Dimona; Datawarehouse Labour Market and Social Security. Notes: Standard errors in parentheses. ${ }^{*},{ }^{* *}$ and ${ }^{* * *}$ stand for 10,5 and $1 \%$ significance respectively. The imputed coefficients $\gamma$ and $\beta$ are calculated as a non-linear combination of estimated coefficients by means of the delta method.

Table 7

Switching to occupations with perfect task overlap.

\begin{tabular}{lllll}
\hline & \multicolumn{3}{c}{$\gamma$} & \multicolumn{2}{c}{$\beta$} \\
$j=1: 100 \%$ & $(1)$ & $(2)$ & $(1)$ & $(2)$ \\
& $0.4419^{* * *}$ & $0.3518^{* * *}$ & $0.8716^{* * *}$ & $0.7219^{* * *}$ \\
$j=2: 80-99 \%$ & $(0.1087)$ & $(0.159)$ & $(0.0517)$ & $(0.0646)$ \\
& $0.2207^{* * *}$ & $0.2846^{* * *}$ & $0.1563^{* * *}$ & $0.1594^{* * *}$ \\
& $(0.0280)$ & $(0.0441)$ & $(0.0176)$ & $(0.0197)$ \\
$j=3: 60-79 \%$ & 0.0116 & 0.0098 & 0.0217 & 0.0210 \\
& $(0.0113)$ & $(0.0142)$ & $(0.0376)$ & $(0.0420)$ \\
$j=4: 30-59 \%$ & 0.0003 & 0.0007 & -0.0072 & -0.0076 \\
& $(0.0007)$ & $(0.0009)$ & $(0.0044)$ & $(0.0049)$ \\
$j=5: 1-29 \%$ & -0.0007 & -0.0008 & 0.0009 & 0.0010 \\
& $(0.0002)$ & $(0.0003)$ & $(0.0005)$ & $(0.0006)$ \\
\hline
\end{tabular}

Source: VDAB: Mijn Loopbaan; Dimona; Datawarehouse Labour Market and Social Security. Notes: Standard errors in parentheses. *, ** and ${ }^{* * *}$ stand for 10,5 and $1 \%$ significance respectively. The imputed coefficients $\gamma$ and $\beta$ are calculated as a non-linear combination of estimated coefficients by means of the delta method.

of this view by redoing our analyses while treating all jobs with which unemployed job seeker $i$ has $100 \%$ task overlap but no listed experience as a separate category in our measures of task distance.

In particular, we now distinguish five groups $j: j=1$ counts all vacancies and other unemployed job seekers in jobs for which $i$ possesses all of the required task competencies but that are not part of $i$ 's listed job experiences; $j=2$ for which there is $80 \%$ to $99 \%$ task overlap; $j=3$ for which there is $60 \%$ to $79 \%$ task overlap; $j=4$ for which there is between $30 \%$ and $59 \%$ task overlap; and $j=5$ for which there is more than $0 \%$ but less than $30 \%$ task overlap.

Table 7 is similar to Table 6 and summarizes imputed estimates for $\gamma_{j}$ and $\beta_{j}$, with columns (1) and (2) referring to the specifications in columns (1) and (2) of Table 5. Coefficients for $j=1$ are significantly below unity. This suggests that unemployed job seekers do not compete equally efficiently for jobs for which they have all of the required task competencies but no listed experience, suggesting the importance of overall adjustment costs of occupational switching. But coefficients for $j=1$ are also significantly above those for $j=2$, suggesting the importance of adjustment costs related to (even small) changes in task content.

\subsubsection{Excluding upward mobility within occupations}

Due to the imposed structure of task measures in ROME-V3, we excluded $100 \%$ task overlap for higher with lower experience levels within the same occupation from our definition of task overlap. However, the analyses so far included task overlap for lower with higher experience levels within the same occupation, for which task overlap will always be less than $100 \%$ by construction of ROME-V3. This, in part, explains why there is a diagonal in Fig. 2: one third of task overlap of at least $80 \%$ is due to overlap with higher experience levels within the same occupation.
The reason for including imperfect task overlap for lower with higher experience levels within the same occupation is that it is intuitive that workers possess some but not all of the task competencies to do the more experienced jobs in their listed occupations. However, job mobility to higher experience levels within the same occupation may simply reflect career mobility in a single job market, thereby inflating our estimates of the importance of task overlap for the probability of finding a job. Therefore, this subsection repeats the analyses in Table 5 while excluding task overlap with higher experience levels within an unemployed job seeker's listed occupations.

Estimates of $\alpha_{1}$ and $\alpha_{2}$ in Table 8 are very similar to those of Table 5. Coefficients on $V_{i}^{\text {all }} / V_{i}$ are somewhat higher and on $U_{i}^{\text {all }} / U_{i}$ somewhat lower than in Table 5, resulting in imputed values for $\gamma_{1}$ and $\beta_{1}$ that are somewhat lower, suggesting that lower experience levels compete to some extent with higher experience levels within the same occupations. But imputed values for $\gamma_{1}$ and $\beta_{1}$ remain statistically significant, indicating that occupational careers are one reason, but not the only reason, why job markets overlap because of common task contents.

\subsubsection{Results without the linearisation of job finding probabilities}

The right-hand side of Eq. (6) is a first-order linear approximation. To see whether this linearisation is in part driving our results, this subsection provides an alternative approach to estimating the importance of task overlap for hazard rates. Specifically, we estimate our model separately for each $j=1, \ldots, 4$ :

$h\left(\tau_{i}\right)=k \tau_{i}^{k-1} \exp \left[v_{1 j} \ln \left(V_{i j}\right)+v_{2 j} \ln \left(U_{i j}\right)+X_{i}^{\prime} \delta\right]$

where $X_{i}$ contains the same controls as in column (2) of Table 4.

Results are reported in Table 9: to save space, coefficients on controls are not reported as these all have the expected signs. For comparison, column (1) of Table 9 replicates the estimates for $\alpha_{1}$ and $\alpha_{2}$ in the first two rows of column (2) in Table 4 by setting $V_{i j}=V_{i}^{\text {all }}$ and $U_{i j}=U_{i}^{\text {all }}$ in Eq. (7).

Allowing for task overlap, parameter $v_{1 j}$ captures $\alpha_{1} \gamma_{j}$ and $v_{2 j}$ captures $\alpha_{2} \beta_{j}$. If $\gamma_{j}$ and $\beta_{j}$ are strictly positive and decreasing in $j$, we would expect the same of $v_{1 j}$ and $v_{2 j}$. Results shown in columns (2) to (5) for $j=1, \ldots, 4$ show that this is indeed the case. Moreover, the substantial decrease between columns (1) and (2) suggests that $\gamma_{1}$ and $\beta_{1}$ are substantially below one, in line with our previous results. Estimates of $v_{1 j}$ and $\nu_{2 j}$ for $j=2,3,4$ are close to unity, suggesting that $\gamma_{j}$ and $\beta_{j}$ for $j=2,3,4$ are close to zero, again in line with our previous findings. ${ }^{27}$

\footnotetext{
27 Because not every job seeker will have overlap with jobs for every taskoverlap bin, the number of observations differs between the columns. For example, a job seeker that doesn't have overlap with any job is not included in any of the columns (2) to (5). By construction, a profile of task competencies is more likely to have at least one overlapping job that has $30 \%$ or less tasks in common than jobs that have $80 \%$ task overlap. Therefore, we have more observations in column (5) than in columns (2), (3) or (4). Also, task overlap between $60 \%$ and $79 \%$ is least common, thereby explaining the lowest number of observations in column (3).
} 
Table 8

Explaining Job finding probabilities excluding occupational careers.

\begin{tabular}{|c|c|c|c|c|}
\hline Variables & $\begin{array}{l}\text { (1) } \\
\text { odds ratio }\end{array}$ & $\begin{array}{l}\text { (2) } \\
\text { odds ratio }\end{array}$ & $\begin{array}{l}\text { (3) } \\
\text { odds ratio }\end{array}$ & $\begin{array}{l}\text { (4) } \\
\text { odds ratio }\end{array}$ \\
\hline $\ln V_{i}$ & $\begin{array}{l}1.122^{* * * *} \\
(0.004)\end{array}$ & $\begin{array}{l}1.131^{* * *} \\
(0.005)\end{array}$ & $\begin{array}{l}1.106^{* * *} \\
(0.005)\end{array}$ & $\begin{array}{l}1.118^{* * *} \\
(0.005)\end{array}$ \\
\hline $\ln U_{i}$ & $\begin{array}{l}0.928^{* * *} \\
(0.004)\end{array}$ & $\begin{array}{l}0.929^{* * * *} \\
(0.004)\end{array}$ & $\begin{array}{l}0.950^{* * *} \\
(0.004)\end{array}$ & $\begin{array}{l}0.947 * * * \\
(0.004)\end{array}$ \\
\hline$V_{i}^{\text {all }} / V_{i}$ & $\begin{array}{l}1.282^{* * * *} \\
(0.037)\end{array}$ & $\begin{array}{l}1.312^{* * * *} \\
(0.038)\end{array}$ & $\begin{array}{l}1.296^{* * * *} \\
(0.038)\end{array}$ & $\begin{array}{l}1.320^{* * * *} \\
(0.039)\end{array}$ \\
\hline$U_{i}^{\text {all }} / U_{i}$ & $\begin{array}{l}0.793^{* * * *} \\
(0.026)\end{array}$ & $\begin{array}{l}0.771^{* * *} \\
(0.025)\end{array}$ & $\begin{array}{l}0.746^{* * * *} \\
(0.025)\end{array}$ & $\begin{array}{l}0.736^{* * * *} \\
(0.025)\end{array}$ \\
\hline$V_{i 2}^{\text {some }} / V_{i}$ & $\begin{array}{l}1.006 \\
(0.005)\end{array}$ & $\begin{array}{l}1.005 \\
(0.006)\end{array}$ & $\begin{array}{l}1.001 \\
(0.006)\end{array}$ & $\begin{array}{l}1.002 \\
(0.006)\end{array}$ \\
\hline$V_{i 3}^{\text {some }} / V_{i}$ & $\begin{array}{l}1.001 \\
(0.000)\end{array}$ & $\begin{array}{l}1.001 \\
(0.000)\end{array}$ & $\begin{array}{l}1.001 \\
(0.000)\end{array}$ & $\begin{array}{l}1.001 \\
(0.000)\end{array}$ \\
\hline$V_{i 4}^{\text {some }} / V_{i}$ & $\begin{array}{l}1.000^{* * *} \\
(0.000)\end{array}$ & $\begin{array}{l}1.000^{* *} \\
(0.000)\end{array}$ & $\begin{array}{l}1.000^{* * *} \\
(0.000)\end{array}$ & $\begin{array}{l}1.000^{* *} \\
(0.000)\end{array}$ \\
\hline$U_{i 2}^{\text {some }} / U_{i}$ & $\begin{array}{l}1.002 \\
(0.023)\end{array}$ & $\begin{array}{l}1.009 \\
(0.023)\end{array}$ & $\begin{array}{l}1.023 \\
(0.020)\end{array}$ & $\begin{array}{l}1.025 \\
(0.020)\end{array}$ \\
\hline$U_{i 3}^{\text {some }} / U_{i}$ & $\begin{array}{l}1.001 \\
(0.002)\end{array}$ & $\begin{array}{l}1.002 \\
(0.002)\end{array}$ & $\begin{array}{l}1.003 \\
(0.002)\end{array}$ & $\begin{array}{l}1.003 \\
(0.002)\end{array}$ \\
\hline$U_{i 4}^{\text {some }} / U_{i}$ & $\begin{array}{l}1.000 \\
(0.000)\end{array}$ & $\begin{array}{l}1.000 \\
(0.000)\end{array}$ & $\begin{array}{l}1.000 \\
(0.000)\end{array}$ & $\begin{array}{l}1.000 \\
(0.000)\end{array}$ \\
\hline Female & & $\begin{array}{l}0.971^{* * * *} \\
(0.009)\end{array}$ & & $\begin{array}{l}0.962^{* * *} \\
(0.009)\end{array}$ \\
\hline Part-time & & $\begin{array}{l}0.759^{* * * *} \\
(0.012)\end{array}$ & & $\begin{array}{l}0.770^{* * * *} \\
(0.013)\end{array}$ \\
\hline Part-time or full-time & & $\begin{array}{l}0.916^{* * * *} \\
(0.009)\end{array}$ & & $\begin{array}{l}0.913^{* * * *} \\
(0.009)\end{array}$ \\
\hline Belgian nationality: acquired & & $\begin{array}{l}0.886^{* * * *} \\
(0.010)\end{array}$ & & $\begin{array}{l}0.904^{* * *} \\
(0.011)\end{array}$ \\
\hline Foreign, EU nationality & & $\begin{array}{l}0.821^{* * *} \\
(0.014)\end{array}$ & & $\begin{array}{l}0.843^{* * *} \\
(0.015)\end{array}$ \\
\hline Foreign, other nationality & & $\begin{array}{l}0.909^{* * * *} \\
(0.014)\end{array}$ & & $\begin{array}{l}0.952^{* * * *} \\
(0.015)\end{array}$ \\
\hline High School & & & $\begin{array}{l}1.259^{* * * *} \\
(0.016)\end{array}$ & $\begin{array}{l}1.222^{* * * *} \\
(0.016)\end{array}$ \\
\hline College & & & $\begin{array}{l}1.356^{* * * *} \\
(0.021)\end{array}$ & $\begin{array}{l}1.316^{* * * *} \\
(0.021)\end{array}$ \\
\hline Constant & $\begin{array}{l}0.403^{* * *} \\
(0.001)\end{array}$ & $\begin{array}{l}0.390^{* * *} \\
(0.015)\end{array}$ & $\begin{array}{l}0.403^{* * * *} \\
(0.011)\end{array}$ & $\begin{array}{l}0.317^{* * * *} \\
(0.013)\end{array}$ \\
\hline Observations & 134,722 & 132,187 & 130,361 & 127,913 \\
\hline Location FE & NO & YES & NO & YES \\
\hline Time FE & NO & YES & NO & YES \\
\hline Weibull $k$ & 0.403 & 0.411 & 0.403 & 0.411 \\
\hline
\end{tabular}

Source: VDAB: Mijn Loopbaan; Dimona; Datawarehouse Labour Market and Social Security. Notes: Standard errors in parentheses. * , ** and ${ }^{* * *}$ stand for 10,5 and $1 \%$ statistical significance respectively.

In sum, Table 9 complements our main finding that labour markets are organised along jobs and their task contents, but that unemployed job seekers do not compete in markets where they possess only part of the required task competencies.

\subsubsection{Redefining jobs to include geographic location}

The analysis so far defined an unemployed job seeker's labour market in terms of jobs, defined as occupation-experience cells and their task content. Although some of our estimates included location (i.e. 3-digit NUTS region of residence of unemployed job seekers taken from Datawarehouse Labour Market and Social Security) to control for location specific shocks, an unemployed job seeker's labour market was defined irrespective of location. However, Manning and Petrongolo (2017) examine the importance of overlap between local labour markets, with overlap resulting from a job seeker's place of residence (in a local labour market) and her commuting distance (possibly into neighbouring local labour markets). They find that variation in tightness in neighbouring local labour markets does not largely affect an unemployed job seeker's job finding probability.

What this implies is that our estimates above of the importance of search externalities in job markets with various degrees of task overlap could be too low. For example, estimates for $\alpha_{1}$ and $\alpha_{2}$ in Table 4 could be too low if $V_{i}^{\text {all }}$ and $U_{i}^{\text {all }}$ also include vacancies and other unemployed job seekers for jobs for which $i$ fully qualifies in terms of her task competencies but that are geographically too distant to matter. To account for this, we again estimate the specification of Table 4 after having redefined a job as an occupation-experience cell in a location.

The results are shown in Table 10. For unemployed job seekers we include their places of residence, i.e. 3-digit NUTS regions that were also used in the location fixed effects above, aggregated into three broader groups that capture the west, middle and east of Flanders. Vacancies are redefined similarly using a firm's location. The coefficients are similar to those in Table 4 and, if anything, even somewhat smaller in size. In any case, these results confirm that a possible mismeasurement of jobs and job markets by ignoring geographical location is negligible in our sample.

\section{Heterogeneity across task-competency profiles}

So far, all jobs were pooled in the analyses. However, there could exist heterogeneity in the importance of job markets and their task overlap. For example, the task literature has extensively focussed on routine versus non-routine and cognitive versus manual jobs when analysing the 
Table 9

Explaining job finding probabilities by degree of task overlap.

\begin{tabular}{|c|c|c|c|c|c|}
\hline Variables & $\begin{array}{l}\text { (1) } \\
\text { odds ratio }\end{array}$ & $\begin{array}{l}\text { (2) } \\
\text { odds ratio }\end{array}$ & $\begin{array}{l}\text { (3) } \\
\text { odds ratio }\end{array}$ & $\begin{array}{l}\text { (4) } \\
\text { odds ratio }\end{array}$ & $\begin{array}{l}\text { (5) } \\
\text { odds ratio }\end{array}$ \\
\hline $\ln V_{i}^{\text {all }}$ & $\begin{array}{l}\text { no overlap } \\
1.134^{* * * *} \\
(0.004)\end{array}$ & $j=1$ & $j=2$ & $j=3$ & $j=4$ \\
\hline $\ln U_{i}^{\text {all }}$ & $\begin{array}{l}0.925^{* * * *} \\
(0.003)\end{array}$ & & & & \\
\hline $\ln V_{i 1}^{\text {some }}$ & & $\begin{array}{l}1.025^{* * *} \\
(0.003)\end{array}$ & & & \\
\hline $\ln U_{i 1}^{\text {some }}$ & & $\begin{array}{l}1.016^{* * * *} \\
(0.004)\end{array}$ & & & \\
\hline $\ln V_{i 2}^{\text {some }}$ & & & $\begin{array}{l}1.020^{* * *} \\
(0.005)\end{array}$ & & \\
\hline $\ln U_{i 2}^{\text {some }}$ & & & $\begin{array}{l}0.972^{* * *} \\
(0.005)\end{array}$ & & \\
\hline $\ln V_{i 3}^{\text {some }}$ & & & & $\begin{array}{l}0.994 \\
(0.004)\end{array}$ & \\
\hline $\ln U_{i 3}^{\text {some }}$ & & & & $\begin{array}{l}1.002 \\
(0.004)\end{array}$ & \\
\hline $\ln V_{i 4}^{\text {some }}$ & & & & & $\begin{array}{l}0.990^{* *} \\
(0.005)\end{array}$ \\
\hline $\ln U_{i 4}^{\text {some }}$ & & & & & $\begin{array}{l}1.002 \\
(0.006)\end{array}$ \\
\hline Constant & $\begin{array}{l}0.398^{* * *} \\
(0.011)\end{array}$ & $\begin{array}{l}0.416^{* * * *} \\
(0.011)\end{array}$ & $\begin{array}{l}0.424^{* * *} \\
(0.021)\end{array}$ & $\begin{array}{l}0.387^{* * *} \\
(0.012)\end{array}$ & $\begin{array}{l}0.404^{* * *} \\
(0.014)\end{array}$ \\
\hline Observations & 130,928 & 96,623 & 35,223 & 107,231 & 122,294 \\
\hline Controls & YES & YES & YES & YES & YES \\
\hline Weibull $k$ & 0.412 & 0.416 & 0.424 & 0.404 & 0.402 \\
\hline
\end{tabular}

Source: VDAB: Mijn Loopbaan; Dimona; Datawarehouse Labour Market and Social Security. Notes: Standard errors in parentheses. ${ }^{*},{ }^{* *}$ and ${ }^{* * *}$ stand for 10,5 and $1 \%$ statistical significance respectively.

impact of ongoing automation or offshoring - see Autor (2013) for an overview.

An interesting question in our setting therefore is whether job markets differ between unemployed job seekers with routine versus nonroutine or cognitive versus manual task competencies. For example, it could be that task overlap matters much more for unemployed job seekers with cognitive instead of manual task competencies. Alternatively, it could also be that task overlap is unimportant irrespective of whether an unemployed job seeker's task competencies are routine, cognitive or manual.

Section 5.1 defines non-routine cognitive, routine cognitive, nonroutine manual and routine manual tasks in ROME-V3. Section 5.2 then repeats our main analyses separately for each group of unemployed job seekers with non-routine cognitive, routine cognitive, non-routine manual and routine manual task-competency profiles.

\subsection{Routine, cognitive and manual tasks}

To identify which jobs are routine, we use three groups of tasks in ROME-V3. Firstly, tasks related to the logging of activity data and the sharing of information. Examples are counting and registering the number of pieces produced; or collecting and disseminating information about irregularities in the production process. Secondly, tasks related to assembly line work are also labelled as routine. Examples are providing workstations with materials or checking the stock; clearing and cleaning the work area of materials; or monitoring the flow and progress of products on a production or transport line and, if necessary, unblock and remove elements. Thirdly, some administrative tasks are also classified as routine. Examples are registering and sorting of mail; coding and classifying and archiving of documents; searching, sending and managing of documents; checking the availability of products; or registering of orders.

Based on this classification, we calculate the share of routine tasks in every occupation-experience cell in ROME-V3. Fig. 5 shows the average of this share across jobs within each 2-digit ISCO88 occupation group.

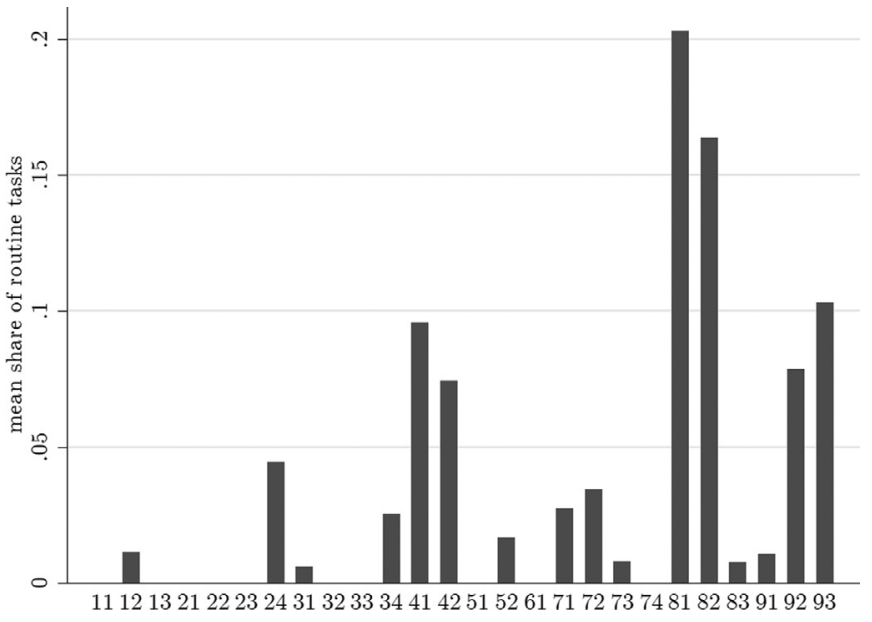

Fig. 5. Mean Share of Routine Tasks in Jobs by ISCO88 Groups. Source: ROMEV3.

For example, the average fraction of tasks that are routine across jobs in 2-digit ISCO88 occupation group "stationary-plant and related operators" (81) is $20 \%$. Fig. 5 shows that routine task intensity is also high for "office clerks" (41); "machine operators and assemblers" (82); "agriculture, fishery and related labourers"(92); "laborers in mining, construction, manufacturing and transport" (93); and "customer services clerks" (42). By and large, this variation corresponds to other occupational measures capturing routine task intensity, such as those reported in Table 1 of Goos et al. (2014). ${ }^{28}$

${ }^{28}$ One difference with Goos et al. (2014) is that routine intensity for occupation groups (73) and (74) is higher in their data than in ours. However, Table 1 shows that these occupation groups only contain $1.46 \%$ of unemployed job seekers in our sample. 
Table 10

Explaining job finding probabilities when jobs include location.

\begin{tabular}{|c|c|c|c|c|}
\hline Variables & $\begin{array}{l}\text { (1) } \\
\text { odds ratio }\end{array}$ & $\begin{array}{l}\text { (2) } \\
\text { odds ratio }\end{array}$ & $\begin{array}{l}\text { (3) } \\
\text { odds ratio }\end{array}$ & $\begin{array}{l}\text { (4) } \\
\text { odds ratio }\end{array}$ \\
\hline $\ln V_{i}^{\text {all }}$ & $\begin{array}{l}1.094^{* * * *} \\
(0.004)\end{array}$ & $\begin{array}{l}1.096 * * * \\
(0.004)\end{array}$ & $\begin{array}{l}1.084^{* * * *} \\
(0.004)\end{array}$ & $\begin{array}{l}1.100^{* * * *} \\
(0.004)\end{array}$ \\
\hline $\ln U_{i}^{\text {all }}$ & $\begin{array}{l}0.932^{* * * *} \\
(0.004)\end{array}$ & $\begin{array}{l}0.936 * * * \\
(0.004)\end{array}$ & $\begin{array}{l}0.948^{* * *} \\
(0.004)\end{array}$ & $\begin{array}{l}0.953^{* * * *} \\
(0.004)\end{array}$ \\
\hline Female & & $\begin{array}{l}0.977^{* *} \\
(0.009)\end{array}$ & & $\begin{array}{l}0.914^{* * * *} \\
(0.008)\end{array}$ \\
\hline Belgian nationality: acquired & & $\begin{array}{l}0.874^{* * * *} \\
(0.010)\end{array}$ & & $\begin{array}{l}0.910^{* * * *} \\
(0.011)\end{array}$ \\
\hline Foreign, EU nationality & & $\begin{array}{l}0.801^{* * *} \\
(0.014)\end{array}$ & & $\begin{array}{l}0.842^{* * * *} \\
(0.016)\end{array}$ \\
\hline Foreign, other nationality & & $\begin{array}{l}0.890^{* * * *} \\
(0.014)\end{array}$ & & $\begin{array}{l}0.964 * * \\
(0.015)\end{array}$ \\
\hline Part-time & & $\begin{array}{l}0.757^{* * *} \\
(0.013)\end{array}$ & & \\
\hline Part-time or full-time & & $\begin{array}{l}0.921 * * * \\
(0.009)\end{array}$ & & \\
\hline High School & & & $\begin{array}{l}1.261^{* * * *} \\
(0.016)\end{array}$ & $\begin{array}{l}1.231^{* * *} \\
(0.016)\end{array}$ \\
\hline College & & & $\begin{array}{l}1.340^{* * * *} \\
(0.021)\end{array}$ & $\begin{array}{l}1.337^{* * * *} \\
(0.021)\end{array}$ \\
\hline Constant & $\begin{array}{l}0.466^{* * * *} \\
(0.001)\end{array}$ & $\begin{array}{l}0.448^{* * * *} \\
(0.008)\end{array}$ & $\begin{array}{l}0.360^{* * * *} \\
(0.007)\end{array}$ & $\begin{array}{l}0.322^{* * * *} \\
(0.010)\end{array}$ \\
\hline Observations & 123,116 & 122,801 & 119,350 & 119,042 \\
\hline Location FE & NO & YES & NO & YES \\
\hline Time FE & NO & YES & NO & YES \\
\hline Weibull $k$ & 0.406 & 0.412 & 0.406 & 0.412 \\
\hline
\end{tabular}

Source: VDAB: Mijn Loopbaan; Dimona; Datawarehouse Labour Market and Social Security. Notes: Standard errors in parentheses. ${ }^{*}{ }^{* *}$ and ${ }^{* * *}$ stand for 10,5 and $1 \%$ statistical significance respectively.

To further distinguish between cognitive versus manual jobs, we assume that all ISCO 88 occupations starting with digits 1 to 4 are cognitive jobs, whereas those ISCO88 occupations starting with digits 5 to 9 are considered to be manual jobs.

\subsection{Is there heterogeneity across unemployed job seekers?}

The subsection above defined types of jobs by their task content, not groups of unemployed job seekers by their task-competencies. To do this, define the $50 \%$ of unemployed job seekers with most experience in routine tasks as having routine-task competencies, whereas the other half of unemployed job seekers is assumed to have non-routine task competencies. To further distinguish between unemployed job seekers with cognitive versus manual task competencies, we make use of the ISCO88 occupation code of their first listed job when registering on the platform. This way, we end up with the following four types of unemployed job seekers based on their task competencies: non-routine cognitive, routine cognitive, non-routine manual and routine manual.

If, for example, unemployed job seekers with cognitive task competencies have higher mobility into jobs, we would expect $\alpha_{1}, \gamma_{j}$ and $\beta_{j}$ to be larger and $\alpha_{2}$ to be smaller compared to job seekers with manual task competencies. Therefore, Table 11 shows point estimates based on a re-estimation of column (2) in Table 5 for unemployed job seekers with non-routine cognitive, routine cognitive, non-routine manual and routine manual task competencies separately. The first row are direct estimates of $\alpha_{1}$ and $\alpha_{2}$, corresponding to the first and second rows in column (2) of Table 5 respectively. All other rows are imputed estimates of $\gamma_{j}$ and $\beta_{j}$, corresponding to the imputed estimates in the second column of Table $6 .{ }^{29}$

Overall, estimates in Table 11 are very similar to those presented in Tables 5 and 6, suggesting that heterogeneity in search externalities and task overlap across job markets that differ by their task content

\footnotetext{
${ }^{29}$ Estimates for $\delta$ are not shown and remain qualitatively identical.
}

is limited. For example, the overall limited importance of task overlap documented in Table 11 implies that job markets are relatively insular, independent of a job seeker's task competencies. However, Table 11 also shows some small but noticeable differences between job seekers with different task competencies: Search externalities and task overlap are more important for unemployed job seekers with cognitive and routine task competencies.

\section{Winners and losers from automation}

The previous section argued that heterogeneity in task overlap between unemployed job seekers with different task competencies is limited. This insularity of job markets, together with how unemployed job seekers are distributed across task competencies, implies that taskbiased shocks might have important distributional consequences for changes in hazard rates and unemployment durations. For example, assume a shock that reduces the demand for routine labour task. If task overlap is unimportant, it will be more difficult for unemployed job seekers with routine-task competencies to find new jobs. At the same time, unemployed job seekers with non-routine task competencies remain relatively isolated from such a shock. Consequently, the decrease in hazard rates and increase in unemployment duration differs across unemployed job seekers with routine and non-routine task competencies. That is, there are winners and losers from automation. To the contrary, if task overlap would be important, the impact of a decrease in the demand for routine labour tasks would ripple through various job markets, and the burden of the shock would be more equally distributed across unemployed job seekers with different task competencies.

To quantify this further, this section examines the changes in hazard rates and unemployment durations following an exogenous decrease in routine-task intensive vacancies. One justification for this decrease in routine-task intensive vacancies is that ongoing technological progress is automating routine tasks, as has been argued extensively in the litera- 
Table 11

The importance of task overlap in the probability of finding a job by type of task competencies.

\begin{tabular}{lllllllll}
\hline & \multicolumn{2}{c}{ Non-Routine cognitive } & \multicolumn{2}{c}{ Routine cognitive } & \multicolumn{2}{c}{ Non-Routine manual } & \multicolumn{2}{c}{ Routine manual } \\
& $\alpha_{1}$ & $\alpha_{2}$ & $\alpha_{1}$ & $\alpha_{2}$ & $\alpha_{1}$ & $\alpha_{2}$ & $\alpha_{1}$ & $\alpha_{2}$ \\
& $1.1125^{* * *}$ & $0.9466^{* * *}$ & $1.1943^{* * *}$ & $0.9098^{* * *}$ & $1.094^{* * *}$ & $0.9750^{* * *}$ & $1.1047^{* * *}$ & $0.9262^{* * *}$ \\
& $(0.0104)$ & $(0.0109)$ & $(0.0108)$ & $(0.0090)$ & $(0.0090)$ & $(0.0083)$ & $(0.0140)$ & $(0.0119)$ \\
& $\gamma$ & $\beta$ & $\gamma$ & $\beta$ & $\gamma$ & $\beta$ & $\gamma$ & $\beta$ \\
$j=1: 80-100 \%$ & $0.3163^{* * *}$ & $0.1372^{* * *}$ & $0.5040^{* * *}$ & $0.3919^{* * *}$ & $0.2177^{* * *}$ & $0.1636^{* *}$ & $0.2494^{* * *}$ & $0.2692^{* * *}$ \\
& $(0.0459)$ & $(0.0305)$ & $(0.0769)$ & $(0.1037)$ & $(0.0352)$ & $(0.0646)$ & $(0.0518)$ & $(0.0635)$ \\
$j=2: 60-79 \%$ & $0.0701^{* * *}$ & -0.0701 & $0.0476^{*}$ & $0.4307^{*}$ & 0.0484 & 0.2706 & 0.0179 & -0.6933 \\
& $(0.0271)$ & $(0.0776)$ & $(0.0286)$ & $(0.2471)$ & $(0.0762)$ & $(0.3089)$ & $(0.0324)$ & $(0.4575)$ \\
$j=3: 30-59 \%$ & $0.0045^{* * *}$ & $-0.0225 * * *$ & 0.0004 & 0.0491 & -0.0036 & $-0.0963^{*}$ & $-0.0295^{* * *}$ & $0.3715^{* *}$ \\
& $(0.0017)$ & $(0.0081)$ & $(0.0041)$ & $(0.0374)$ & $(0.0025)$ & $(0.0566)$ & $(0.0109)$ & $(0.1653)$ \\
$j=4: 1-29 \%$ & $-0.0009^{* *}$ & 0.0000 & $0.0013^{* *}$ & $-0.0018^{*}$ & $-0.0009^{*}$ & 0.0033 & -0.0001 & -0.0006 \\
& $(0.0004)$ & $(0.0014)$ & $(0.0006)$ & $(0.0010)$ & $(0.0005)$ & $(0.0033)$ & $(0.0017)$ & $(0.0034)$ \\
$N$ & & 34,321 & & 35,806 & & 32,654 & & 25,965 \\
\hline
\end{tabular}

Source: VDAB: Mijn Loopbaan; Dimona; Datawarehouse Labour Market and Social Security. Notes: Standard errors in parentheses. ${ }^{*},{ }^{* *}$ and ${ }^{* * *}$ stand for 10,5 and $1 \%$ significance respectively. The imputed coefficients $\gamma$ and $\beta$ are calculated as a non-linear combination of estimated coefficients by means of the delta method. The controls included in the estimations are identical to the specification in column (2) of Table 5

ture ${ }^{30}$ Consequently, unemployed job seekers with routine-task competencies see larger decreases in their hazard rates and increases in their unemployment durations.

To predict the impact of a negative routine-biased task shock to vacancies on job seekers' hazard rates, we use Eq. (6) and parameter estimates shown in column (2) of Table 5:

$\hat{T}_{i}+X_{i}^{\prime} \hat{\delta} \approx 0.12 \ln \left(V_{i}\right)-0.08 \ln \left(U_{i}\right)+0.24 \frac{V_{i}^{\text {all }}}{V_{i}}-0.21 \frac{U_{i}^{\text {all }}}{U_{i}}+X_{i}^{\prime} \hat{\delta}$ $+0.01 \frac{V_{i 2}^{\text {some }}}{\frac{V_{j}}{V_{j}}}+0.00 \frac{V_{i 3}^{\text {some }}}{V_{j}}-0.00 \frac{V_{i 4}^{\text {some }}}{V_{j}}$

$$
+0.02 \frac{U_{i 2}^{\text {some }}}{U_{i}}+0.00 \frac{U_{i 3}^{V_{i j}}}{U_{i}}-0.00 \frac{U_{i 4}^{U_{i}}}{U_{i}}
$$

Substituting Eq. (8) into Eq. (3), we predict two hazard rates for each job seeker $i{ }^{31}$ The first prediction uses i's actual relevant vacancies $V_{i}, V_{i}^{\text {all }}$, and $V_{i j}^{\text {some }}$ for $j=2,3,4$. The second prediction uses a counterfactual set of vacancies assuming a reduced demand for routine labour tasks to capture automation. In particular, we assume a $25 \%$ reduction of vacancies multiplied by the share of routine tasks in each job. For example, if $50 \%$ of all tasks in a job are routine, the number of vacancies for that job is reduced by $12.5 \% .{ }^{32}$ Finally, for each unemployed job seeker $i$ we then calculate the percentage change in her hazard rate based on her actual and counterfactual set of relevant vacancies.

Fig. 6 shows the cumulative distribution of percentage changes in hazard rates across all job seekers. It is clear from the figure that the hazard rate decreases on average, as would be expected from a negative shock to vacancies. However, it is also clear that the impact of the shock is distributed unequally across unemployed job seekers. In particular, Fig. 5 showed that routine tasks are concentrated in 2-digit ISCO88 groups 41, 42, 81, 82, 92, and 93. Also, columns (1) and (2) of Table 1 showed that these 2-digit ISCO88 groups capture over $30 \%$ of all task competencies of unemployed job seekers. That is, automation

\footnotetext{
${ }^{30}$ Automation could also result in an increase in the number of unemployed job seekers with routine task competencies and/or the creation of new vacancies requiring non-routine task competencies. All of these changes result in a decrease of labour market tightness in job markets for routine relative to nonroutine task competencies, which is the variation that is used in our calculations below.

${ }^{31}$ Setting the coefficients for $\gamma_{j}$ and $\beta_{j}$ for $j>1$ to zero does not change our results.

${ }^{32}$ Assuming that all vacancies result in jobs, the overall size of this shock corresponds to a 1 percentage-point reduction in the share of routine jobs over the two-year period 2013-2014. This is in the same order of magnitude as (Goos et al., 2014) who find that the change in the share of routine occupations over 1993 to 2010 is 6.84 percentage-points, or around 0.8 percentage-points for every two-year period.
}

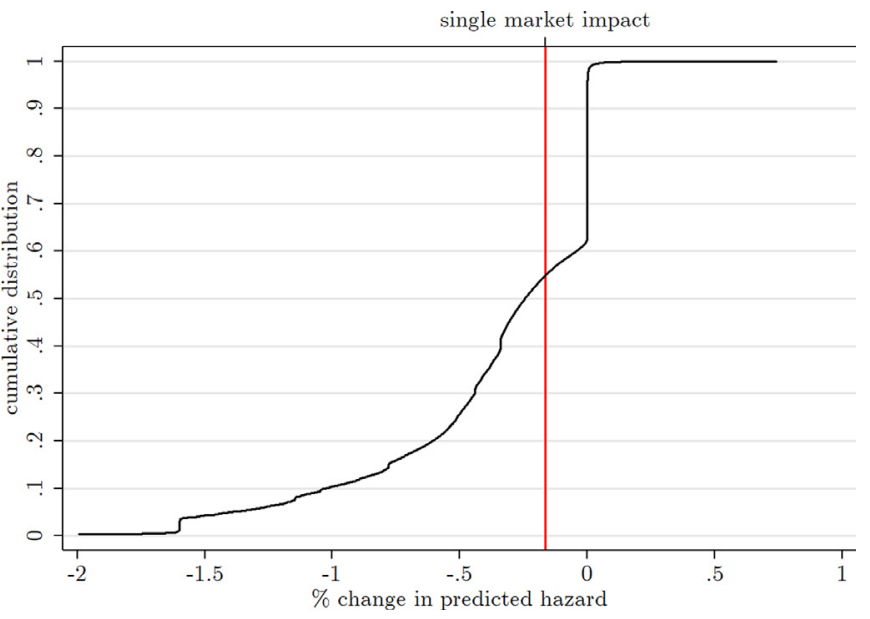

Fig. 6. Distribution of Changes in Hazard Rates from Automation. Source: VDAB: Mijn Loopbaan; Dimona; Datawarehouse Labour Market and Social Security. Notes: The figure is left censored at -2 for clarity. This discards $0.3 \%$ of observations.

disproportionately reduces the job finding probabilities for a sizeable group of unemployed job seekers with routine-task competencies.

To further interpret this result, we compare the cumulative density in Fig. 6 with the impact of the same shock while assuming that there is a single market for all unemployed job seekers, irrespective of their task competencies. In this single market scenario, unemployed job seekers are assumed to be perfectly mobile across jobs, such that tightness must always be equal across job markets. As a result, the burden of any adverse shock in vacancies, even if it's task-biased, will be shared equally across all unemployed job seekers.

To assess the impact of automation in this single market scenario, first define the number of vacancies and other unemployed job seekers relevant to individual $i$ as the sum of all vacancies and job seekers in the aggregate labour market: $V$ and $U$. We can then use Eq. (5) and the parameter estimates in column (2) of Table 4 to predict:

$\hat{T}_{i}=0.13 \ln (V)-0.08 \ln (U)$

Substituting Eq. (9) into Eq. (3), we again predict two hazard rates: one using the actual number of total vacancies $V$, and one assuming a reduction in vacancies that is equal to the reduction in the total number of vacancies in Fig. 6 . In this single market scenario, the hazard rate decreases by $-0.16 \%$ for each unemployed job seeker, given by the vertical line in Fig. 6. The increase in expected unemployment duration corre- 
sponding to this decrease in the hazard rate is $0.40 \%$, or an increase by 0.06 weeks from 15 weeks on average.

Compared to the single market outcome, the cumulative density in Fig. 6 shows that $46 \%$ of unemployed job seekers win (i.e. are right of the vertical line) and $54 \%$ lose (i.e. are left of the vertical line), due to their differences in task competencies that protect winners from and expose losers to automation. Across the 54\% losers, the hazard rate decreases by $-0.64 \%$ on average. Compared to the single market outcome, this decrease is four times as large $(-0.64 \%$ versus $-0.16 \%)$. Also, the average percentage increase in expected unemployment duration across the $54 \%$ losers is $1.57 \%$, or an increase of 0.65 weeks from 36 weeks on average. Compared to the single market outcome, this percentage increase is four times as large $(1.57 \%$ versus $0.40 \%) .{ }^{33}$

In sum, ongoing technological progress has important distributional consequences across unemployed job seekers with different task competencies. We showed that there are winners and losers from automation: relative to a labour market in which task competencies wouldn't matter, the average loser experiences a fourfold decrease in her job finding probability or a fourfold increase in her expected unemployment duration.

\section{Conclusions}

Using data from an online job platform, we find that tightness in jobs for which an unemployed job seeker fully qualifies in terms of her task competencies is predictive of her unemployment duration, suggesting that the labour market is organized along detailed jobs and their task content. We also find that overlap across jobs in terms of their task content matters - i.e. there is mobility of unemployed job seekers into jobs for which they only partially qualify based on their task competencies. However, this mobility is limited because our estimates show that unemployed job seekers cannot successfully compete for jobs for which they do not have the large majority of required task competencies.

These results are a simple illustration of the importance of search in markets for detailed jobs that are linked by their task contents. Following Manning and Petrongolo (2017), one interesting extension would

33 If expressed relative to the single market outcome, the decreases in hazard rates are independent of the assumed size of the shock. For example, reducing the number of vacancies by $50 \%$ instead of $25 \%$ (multiplied by the share of routine tasks in each job) doubles the decrease in the job finding probability for the average loser as well as for the single market outcome, leaving the fourfold percentage difference between both unaffected.
Table A1

Sampling of unemployed job seekers from the VDAB platform.

\begin{tabular}{ll}
\hline Strata & Sampling percentage \\
\hline Newly registered in last month & $20 \%$ \\
1-2 months unemployed & $20 \%$ \\
$2-3$ months unemployed & $20 \%$ \\
$3-6$ months unemployed & $10 \%$ \\
6-12 months unemployed & $10 \%$ \\
More than 12 months unemployed & $5 \%$ \\
\hline
\end{tabular}

Table A2

Sampling of vacancies from the VDAB platform.

\begin{tabular}{ll}
\hline Strata & Sampling percentage \\
\hline Vacancies that closed in the past month & $50 \%$ \\
All outstanding in the past month & $5 \%$
\end{tabular}

be to formalise how individuals with different task competencies direct their applications to vacancies across job markets and to structurally estimate the aggregate matching function that is consistent with this. An alternative extension would be to estimate a full search and matching model with different job islands, endogenous mobility and firm entry to address questions such as the optimal search breadth across job markets that overlap in their task content or to examine equilibrium effects resulting from task-biased shocks.

Our results also imply that some unemployed job seekers cannot easily shield themselves from task-biased shocks: if such shocks decrease tightness in jobs the unemployed worker has task competencies for, they cannot easily move into other, less-exposed, jobs instead. To illustrate this, we quantify the winners and losers from ongoing technological progress: following the automation of routine tasks, unemployed job seekers with routine task competencies experience a fourfold increase in their unemployment durations compared to a single labour market in which differences in task competencies wouldn't matter.

These results suggest that there is only limited scope for policies that, for given task competencies, direct unemployed job seekers with routine-task competencies to less routine-task intensive vacancies for which they also in part qualify. Given the importance of labour market tightness in our analyses, alternative policies could direct those unemployed job seekers to jobs not only for which they partially qualify but also in which there is high labour market tightness.
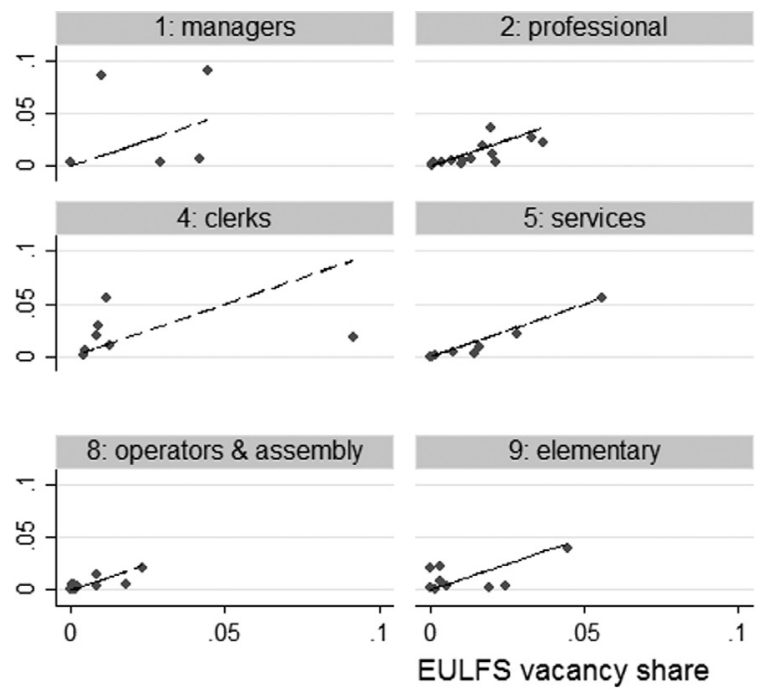

sample vacancy share

\section{3: assoc. professiona}

$\bullet$
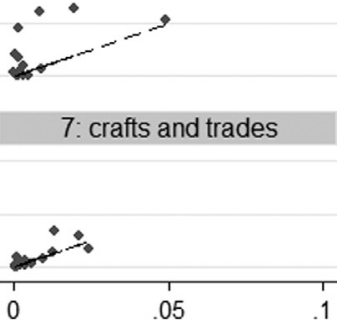

Fig. A1. Vacancy Shares at the 3-digit ISCO88 level by 1digit group. Source: VDAB: Mijn Loopbaan; BELSTAT. 
Interesting extensions would therefore be to use online job platforms to evaluate the impact of informational campaigns aimed at directing certain unemployed job seekers to jobs for which they partially qualify or to jobs with a higher ratio of vacancies to job seekers. Belot et al. (2016) conduct a lab experiment that provides evidence in support of information as a barrier to job mobility: redirecting individuals towards tight labour markets increases their chance of getting a job interview. Such algorithmic recommendations are low cost and could be widely tested and implemented on public and private job platforms in practice.

\section{Appendix A. The VDAB sample}

\section{A1. Sampling weights}

Unemployed job seekers are sampled from the platform at the end of the first month of every quarter in 2013-2014, resulting in 8 crosssections of unemployed job seekers. Because random sampling in these cross-sections would result in an over-representation of the long termed unemployed, each cross-section over-samples unemployed job seekers with shorter durations using the percentages listed in Table A.1. We apply the inverse of the sampling probabilities to ensure representativeness of unemployed job seekers throughout our duration analyses. Moreover, each observation is weighted by the inverse of the total number of jobs listed by an unemployed job seeker when registering on the platform.

Table A. 2 shows how vacancies are sampled from the platform at the end of the first months of every quarter in 2013-2014. To make sure the sampling procedure represents the high turnover rate in vacancies, our sample contains $50 \%$ of all vacancies that closed in the month before sampling and $5 \%$ of all vacancies registered on the platform in the month before sampling. Because some vacancies are sampled twice in this stratification, we use the unique combination of all vacancies sampled, dropping any duplicates, to calculate the stock of vacancies. Again, we apply the inverse of the sampling probabilities to ensure representativeness of vacancies throughout our duration analyses.

\section{A2. Representativeness of vacancies in the VDAB sample}

To assess the representativeness of our vacancy data, we compare the share of vacancies across 3-digit ISCO88 occupation groups in our VDAB sample to vacancy information from a representative survey of Flemish firms provided by Belgium's Office of National Statistics. Fig. A.1 plots the VDAB sample share (on the vertical axis) against the representative survey share (on the horizontal axis) by 1-digit ISCO88 occupation group and adding a 45-degree line to each panel. In general, shares are relatively close to the 45-degree line, suggesting that the composition of vacancies across occupations in our VDAB sample is representative of the labor market as a whole. ${ }^{34}$

\section{Appendix B. Linearization of tightness with task overlap across jobs}

Following Manning and Petrongolo (2017), we apply a linear approximation to estimate $\gamma_{j}$ and $\beta_{j}$. Substituting Eq. (2) into (1) results in:

$T_{i}=\alpha_{1} \ln \left(V_{i}^{\text {all }}+\sum_{j=1}^{4} \gamma_{j} V_{i j}^{\text {some }}\right)+\alpha_{2} \ln \left(U_{i}^{\text {all }}+\sum_{j=1}^{4} \beta_{j} U_{i j}^{\text {some }}\right)$

\footnotetext{
34 Two exceptions are managing and associate professional occupations. For associate professional occupations, the platform seems to have a overrepresentation of vacancies. It could be for example, that vacancies from labour market intermediaries which are systematically harvested are not representative for these jobs. Such mismeasurement in the true variation of vacancies may lead to some bias in our estimates.
}

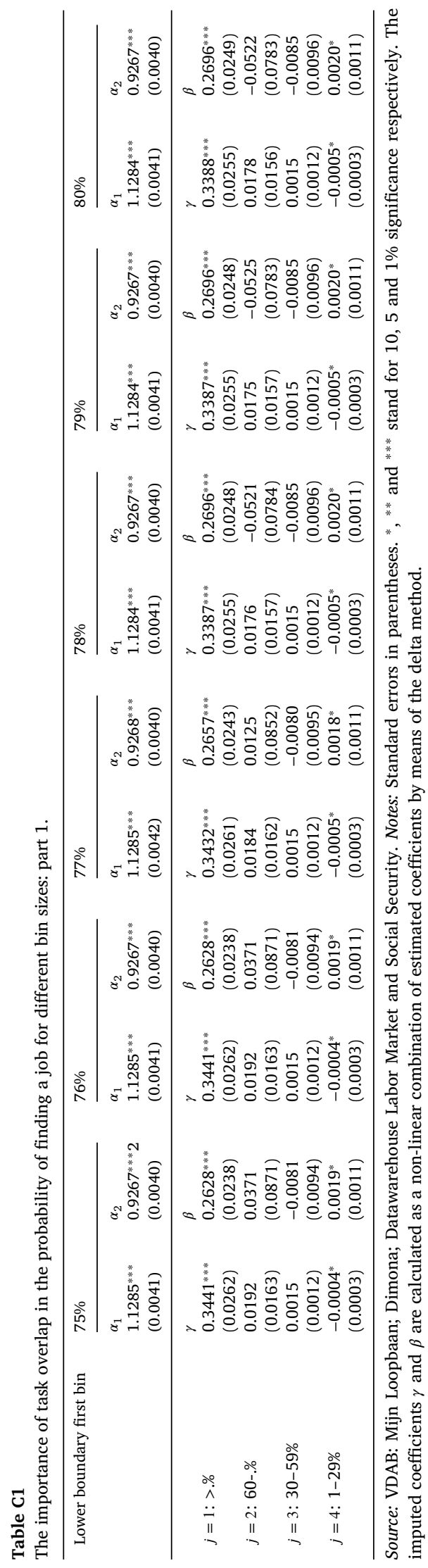


which is not linear in parameters $\alpha_{1}$ and $\gamma_{j}$ or in $\alpha_{2}$ and $\beta_{j}$. To linearise, first define $V_{i}=V_{i}^{\text {all }}+V_{i 1}^{\text {some }}$ and $U_{i}=U_{i}^{\text {all }}+U_{i 1}^{\text {some }}$ and rearrange to get:

$$
\begin{aligned}
T_{i} & =\alpha_{1} \ln \left(\gamma_{1} V_{i}+\left(1-\gamma_{1}\right) V_{i}^{\text {all }}+\sum_{j=2}^{4} \gamma_{j} V_{i j}^{\text {some }}\right) \\
& +\alpha_{2} \ln \left(\beta_{1} U_{i}+\left(1-\beta_{1}\right) U_{i}^{\text {all }}+\sum_{j=2}^{4} \beta_{j} U_{i j}^{\text {some }}\right)
\end{aligned}
$$

This can be rewritten as:

$$
\begin{aligned}
T_{i} \quad & \alpha_{1} \ln (\gamma)+\alpha_{2} \ln (\beta)+\alpha_{1} \ln \left(V_{i}\right)+\alpha_{2} \ln \left(U_{i}\right) \\
& +\alpha_{1} \ln \left(1+\frac{\left(1-\gamma_{1}\right)}{\gamma_{1}} \frac{V_{i}^{\text {all }}}{V_{i}}+\sum_{j=2}^{4} \frac{\gamma_{j}}{\gamma_{1}} \frac{V_{i j}^{\text {some }}}{V_{i}}\right) \\
& +\alpha_{2} \ln \left(1+\frac{\left(1-\beta_{1}\right)}{\beta_{1}} \frac{U_{i}^{\text {all }}}{U_{i}}+\sum_{j=2}^{4} \frac{\beta_{j}}{\beta_{1}} \frac{U_{i j}^{\text {some }}}{U_{i}}\right)
\end{aligned}
$$

The terms $T_{i}+X_{i}^{\prime} \delta$ in Eq. (3) can now be approximated using a firstorder Taylor expansion:

$$
\begin{aligned}
& T_{i}+X_{i}^{\prime} \delta \approx \alpha_{1} \ln \left(V_{i}\right)+\alpha_{2} \ln \left(U_{i}\right)+\alpha_{1} \frac{1-\gamma_{1}}{\gamma_{1}} \frac{V_{i}^{\text {all }}}{V_{i}}+\alpha_{2} \frac{1-\beta_{1}}{\beta_{1}} \frac{U_{i}^{\text {all }}}{U_{i}}+X_{i}^{\prime} \delta \\
& +\alpha_{1} \sum_{j=2}^{4} \frac{\gamma_{j}}{\gamma_{1}} \frac{V_{i j}^{\text {some }}}{V_{i}}+\alpha_{2} \sum_{j=2}^{4} \frac{\beta_{j}}{\beta_{1}} \frac{U_{i j}^{\text {some }}}{U_{i}}
\end{aligned}
$$

where $\alpha_{1} \ln (\gamma)+\alpha_{2} \ln (\beta)$ is absorbed by the constant term in $X_{i}$ and its coefficient.

\section{Appendix C. Sensitivity of first bin cut-off}

To test the sensitivity of our results to the choice of $j=1$, Tables C1 and C2 perform robustness analyses. The last column of Table $\mathrm{C} 1$ and the first column of Table $\mathrm{C} 2$ reproduce the estimates in column (2) of Table 6. Both Tables C1 and C2 can be read from left to right, where the estimates are updated as we increase the lower bound for $j=1$ from $75 \%$ to $85 \%$ task overlap. If our empirical approach using bins $j=1, \ldots, 4$ is a rough approximation to a simple (in a conceptual but not empirical sense) monotonic relationship between search externalities and task dissimilarities, increasing the lower bound for $j=1$ would result in an increase in the magnitude and significance of estimates for $\gamma_{1}$ and $\beta_{1}$. However, the evidence in Tables C1 and C2 to support this view is mixed: estimates for $\gamma_{1}$ do not display a particular pattern whereas estimates for $\beta_{1}$ increase somewhat as the lower bound for $j=1$ increases 75 to $85 \%$. Arguably, our bins-approach therefore captures a more complex interplay between search externalities and task overlap than a simple monotonic linear relationship.

\section{References}

Acemoglu, D., Autor, D., 2011. Skills, tasks and technologies: implications for employment and earnings. Handb. Lab. Econ. 4, 1043-1171.

Autor, D., 2013. The 'task approach' to labor markets: an overview. J. Lab. Mark. Res. 46, 185-199.

Autor, D.H., Dorn, D., 2013. The growth of low skill service jobs and the polarization of the U.S. labor market. Am. Econ. Rev. 103(5), 1553-1597.

Autor, D.H., Dorn, D., Hanson, G.H., 2013. The china syndrome: local labor market effects of import competition in the United States. Am. Econ. Rev. 103 (6), 2121-2168. doi:10.1257/aer.103.6.2121.

Autor, D.H., Dorn, D., Hanson, G.H., 2015. Untangling trade and technology: evidence from local labour markets. Econ. J. 125 (584), 621-646. doi:10.1111/ecoj.12245.

Belot, M., Kircher, P., Muller, P., 2016. Providing Advice to Job Seekers at Low Cost: An Experimental Study on Online Advice. IZA Discussion Papers. Institute for the Study of Labor (IZA).

Van den Berg, G.J., 2001. Duration models: specification, identification and multiple durations, Vol. 5. Elsevier, pp. 3381-3460.

van den Berg, G.J., van Ours, J.C., 1996. Unemployment dynamics and duration dependence. J. Lab. Econ. 14 (1), 100-125.

Borowczyk-Martins, D., Jolivet, G., Postel-Vinay, F., 2013. Accounting for endogeneity in matching function estimation. Rev. Econ. Dyn. 16 (3), 440-451. doi:10.1016/j.red.2012.07.001.

Cortes, G.M., Gallipoli, G., 2018. The costs of occupational mobility: an aggregate analysis. J. Eur. Econ. Assoc. 16 (3), 275-315. doi:10.1093/jeea/jvx006.

Cortes, G. M., Jaimovich, N., Nekarda, C. J., Siu, H. E., 2016. The Micro and Macro of Disappearing Routine Jobs: A Flows Approach. Unpublished Manuscript.

Cortes, G.M., Jaimovich, N., Siu, H.E., 2017. Disappearing routine jobs: who, how, and why? J. Monetary Econ. 91, 69-87. doi:10.1016/j.jmoneco.2017.09.006.

Davis, S.J., von Wachter, T.M., 2011. Recessions and the cost of job loss. Brookings Pap. Econ. Act. 43 (2), 1-72 
Dengler, K., Stops, M., Vicari, B., 2016. Occupation-specific matching efficiency. IAB Discussion Paper. Institut fur Arbeitsmarkt- und Berufsforschung (IAB), Nuremberg [Institute for Employment Research, Nuremberg, Germany].

Diamond, P.A., Sahin, A., 2016. Disaggregating the Matching Function. Working paper. National Bureau of Economic Research.

Fahr, R., Sunde, U., 2004. Occupational job creation: patterns and implications. Oxford Econ. Pap. 56 (3), 407-435.

Gathmann, C., Schonberg, U., 2010. How general is human capital? A task-based approach. J. Lab. Econ. 28 (1), 1-49.

Goos, M., Manning, A., Salomons, A., 2014. Explaining job polarization: routine-Biased technological change and offshoring. Am. Econ. Rev. 104 (8), 2509-2526.

Jacobson, L.S., LaLonde, R.J., Sullivan, D.G., 1993. Earnings losses of displaced workers. Am. Econ. Rev. 83 (4), 685-709.

Kroft, K., Lange, F., Notowidigdo, M.J., 2013. Duration dependence and labor market conditions: evidence from a field experiment. Q. J. Econ. 128 (3), 1123-1167. doi:10.1093/qje/qjt015
Manning, A., Petrongolo, B., 2017. How local are labor markets? Evidence from a spatial job search model. Am. Econ. Rev. 107 (10), 2877-2907. doi:10.1257/aer.20131026.

Marinescu, I., Rathelot, R., 2018. Mismatch unemployment and the geography of job search. Am. Econ. J. 10 (3), 42-70. doi:10.1257/mac.20160312.

Petrongolo, B., Pissarides, C.A., 2001. Looking into the black box: a survey of the matching function. J. Econ. Lit. 39 (2), 390-431. doi:10.1257/jel.39.2.390.

Poletaev, M., Robinson, C., 2008. Human capital specificity: evidence from the dictionary of occupational titles and displaced worker surveys, 1984-2000. J. Lab. Econ. 26 (3), $387-420$.

Robinson, C., 2018. Occupational mobility, occupation distance, and specific human capital. J. Hum. Resour. 53 (2), 513-551. doi:10.3368/jhr.53.2.0814-6556R2.

Stops, M., 2014. Job matching across occupational labour markets. Oxford Econ. Pap. 66 (4), 940-958. doi:10.1093/oep/gpu018.

Sullivan, D., von Wachter, T., 2009. Job displacement and mortality: an analysis using administrative data. Q. J. Econ. 124 (3), 1265-1306. doi:10.1162/qjec.2009.124.3.1265. 